\title{
Smoking-Relevant Nicotine Concentration Attenuates the Unfolded Protein Response in Dopaminergic Neurons
}

\author{
Rahul Srinivasan, ${ }^{\star}$ Beverley M. Henley, ${ }^{\star}$ Brandon J. Henderson, Tim Indersmitten, Bruce N. Cohen,

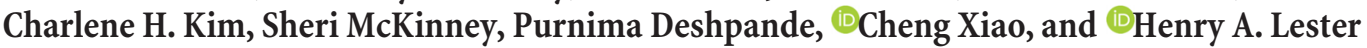 \\ Division of Biology and Biological Engineering, California Institute of Technology, Pasadena, California 91125
}

Retrospective epidemiological studies show an inverse correlation between susceptibility to Parkinson's disease and a person's history of tobacco use. Animal model studies suggest nicotine as a neuroprotective agent and nicotinic acetylcholine (ACh) receptors (nAChRs) as targets for neuroprotection, but the underlying neuroprotective mechanism(s) are unknown. We cultured mouse ventral midbrain neurons for 3 weeks. Ten to $20 \%$ of neurons were dopaminergic (DA), revealed by tyrosine hydroxylase (TH) immunoreactivity. We evoked mild endoplasmic reticulum (ER) stress with tunicamycin (Tu), producing modest increases in the level of nuclear ATF6, phosphorylated eukaryotic initiation factor $2 \alpha$, nuclear XBP1, and the downstream proapoptotic effector nuclear C/EBP homologous protein. We incubated cultures for 2 weeks with $200 \mathrm{~nm}$ nicotine, the approximate steady-state concentration between cigarette smoking or vaping, or during nicotine patch use. Nicotine incubation suppressed Tu-induced ER stress and the unfolded protein response (UPR). Study of mice with fluorescent $\mathrm{nAChR}$ subunits showed that the cultured $\mathrm{TH}+$ neurons displayed $\alpha 4, \alpha 6$, and $\beta 3 \mathrm{nAChR}$ subunit expression and ACh-evoked currents. Gene expression profile in cultures from TH-eGFP mice showed that the TH+ neurons also express several other genes associated with DA release. Nicotine also upregulated ACh-induced currents in DA neurons by $\sim 2.5$-fold. Thus, nicotine, at a concentration too low to activate an appreciable fraction of plasma membrane nAChRs, induces two sequelae of pharmacological chaperoning in the ER: UPR suppression and $\mathrm{nAChR}$ upregulation. Therefore, one mechanism of neuroprotection by nicotine is pharmacological chaperoning, leading to UPR suppression. Measuring this pathway may help in assessing neuroprotection.

Key words: CHOP; eif2alpha; neuroprotection; Parkinson's disease; PERK; XBP1

Significance Statement

Parkinson's disease (PD) cannot yet be cured or prevented. However, many retrospective epidemiological studies reveal that PD is diagnosed less frequently in tobacco users. Existing programs attempting to develop nicotinic drugs that might exert this apparent neuroprotective effect are asking whether agonists, antagonists, partial agonists, or channel blockers show the most promise. The underlying logic resembles the previous development of varenicline for smoking cessation. We studied whether, and how, nicotine produces neuroprotective effects in cultured dopaminergic neurons, an experimentally tractable, mechanistically revealing neuronal system. We show that nicotine, operating via nicotinic receptors, does protect these neurons against endoplasmic reticulum stress. However, the mechanism is probably "inside-out": pharmacological chaperoning in the endoplasmic reticulum. This cellular-level insight could help to guide neuroprotective strategies.

\section{Introduction}

Dopaminergic (DA) neurons are subjected to $\mathrm{Ca}^{+2}$ influx and to potentially toxic byproducts of dopamine metabolism that can

Received June 2, 2015; revised Nov. 9, 2015; accepted Nov. 13, 2015.

Author contributions: R.S., B.M.H., B.J.H., C.X., and H.A.L. designed research; R.S., B.M.H., B.J.H., T.I., B.N.C., C.H.K., S.M., P.D., and C.X. performed research; R.S., B.M.H., B.J.H. contributed unpublished reagents/analytic tools; R.S., B.M.H., B.J.H., T.I., B.N.C., C.X., and H.A.L. analyzed data; R.S., B.M.H., B.J.H., B.N.C., and H.A.L. wrote the paper.

This work was supported by grants from the U.S. National Institutes of Health (AG033954), the Michael J. Fox Foundation, and Louis and Janet Fletcher. We thank Dr. Marie-Françoise Chesselet for useful discussions and E. Mackey for help with antibody verification.

The authors declare no competing financial interests.

${ }^{*}$ R.S. and B.M.H. contributed equally to this work. affect proteostasis (Ahmadi et al., 2008; Miyazaki and Asanuma, 2009; Surmeier et al., 2011). Under normal circumstances, intraorganelle sensors for unfolded or misfolded proteins activate unfolded protein responses (UPRs): homeostatic, adaptive, and compensatory pathways transiently reprogram gene activation, organelle physiology, and catabolic processes. When physiological stresses occur in the context of pathophysiological cellular processes such as aberrant protein folding or chronic exposure to

Correspondence should be addressed to Henry A. Lester, Division of Biology and Biological Engineering, California Institute of Technology, Pasadena, CA 91125. E-mail: lester@caltech.edu.

DOI:10.1523/JNEUROSCI.2126-15.2016

Copyright $\odot 2016$ the authors $\quad 0270-6474 / 16 / 360065-15 \$ 15.00 / 0$ 
environmental toxins, DA neurons display sustained UPR (Mercado et al., 2013). Unmitigated and maintained UPR activates a proapoptotic effector, $\mathrm{C} / \mathrm{EBP}$ homologous protein (CHOP). Several authors suggest that CHOP partially underlies DA cell death and the development of Parkinson's disease (PD; Zinszner et al., 1998; Marciniak et al., 2004; Silva et al., 2005; Galehdar et al., 2010; Mercado et al., 2013).

More than 50 retrospective epidemiological studies since 1959 demonstrated an inverse correlation between a person's history of tobacco use and his or her risk of developing PD. Tobacco use decreases the risk by roughly twofold (Hernán et al., 2002; Tanner et al., 2002; Ritz et al., 2007; Quik and Wonnacott, 2011). On the one hand, this correlation could arise from "inverse causality": in a person with early-stage, preclinical damage to DA neurons, nicotine may stimulate the DA reward pathway less strongly. On the other hand, a genuine neuroprotective effect could appear because decades-long, cumulative neuropathology would be minimized by a maintained protective effect of tobacco. Because there will never be a medical justification for using smoked or smoke-cured tobacco, it is important to understand the mechanism of the apparent or real neuroprotective effect.

Nicotine, the addictive component of tobacco, exerts neuroprotection in in vivo models of Parkinsonism (Maggio et al., 1998; Costa et al., 2001; Ryan et al., 2001; Quik and Wonnacott, 2011). Several mechanisms now allow humans to ingest or consume nearly pure nicotine without the harmful effects of tobacco smoke. These methods include nicotine gum, inhalers, electronic nicotine delivery systems ("e-cigarettes"), and nicotine patches. How can one design a neuroprotective dose regime involving nicotine? Some, but not all, previous clinical trials with nicotine patches show an attenuation of PD symptoms (Fagerstrom et al., 1994; Kelton et al., 2000; Mitsuoka et al., 2002; Villafane et al., 2007), and another, more ambitious, trial is under way (https:// clinicaltrials.gov/show/NCT01560754). These trials all tacitly assume that neuroprotective dosing of nicotine would operate by the same mechanism as the protection against nicotine withdrawal-that is, by achieving the highest tolerable dose of nicotine, to activate or desensitize plasma membrane nicotinic acetylcholine receptors ( $\mathrm{nAChRs}$ ).

However, since 2005, evidence has accumulated that nicotine, when chronically applied at comparatively low doses, acts as a pharmacological chaperone on nAChRs in the endoplasmic reticulum (ER). Activation and desensitization of nAChRs channels is not involved (Henderson and Lester 2015). In overexpression systems, the consequences of pharmacological chaperoning include suppression of ER stress and the UPR (Srinivasan et al., 2012). Another consequence of pharmacological chaperoning is the classically described upregulation of nAChRs (Marks et al., 1985; Schwartz and Kellar, 1985; Henderson and Lester 2015).

To further understand possible neuroprotective mechanisms of nicotine, this study develops and exploits a cultured model for nicotine neuroprotection: endogenously expressed nAChRs in DA neurons. Our experimental strategy involves (1) mild ER stress rather than frank neuronal death and (2) "prolonged" (2 weeks) exposure to concentrations of nicotine attained in blood during smoking ("smoking-relevant" doses). Nicotine attenuates the UPR and prevents CHOP activation following exposure to low doses of the ER stress inducer tunicamycin $(\mathrm{Tu})$. Nicotine neuroprotection can thus be detected at a rather early stage of stress in a reduced system. We show that in DA neurons, nicotine also upregulates natively expressed nAChRs - a hallmark of pharmacological chaperoning. In addition to providing a mech- anism for neuroprotection by nicotine itself, our results suggest strategies for discovering novel drugs that might forestall PD.

\section{Materials and Methods}

Cell culture reagents and chemicals. Neurobasal medium with phenol red, B27 supplement, GlutaMAX, and Hyclone equine serum were purchased from Invitrogen. L-ascorbic acid, (-)-nicotine, poly-Lornithine (P4957), laminin (L2020), papain, and DNase were purchased from Sigma-Aldrich. Tu was purchased from Tocris Bioscience. For long-term cultures, $35 \mathrm{~mm}$ uncoated glass-bottom imaging dishes with a $14 \mathrm{~mm}$ diameter of the imaging area and $0.19 \mathrm{~mm}$ coverslip thickness were purchased from MatTek. Cell culture plasticware was purchased from Grenier Bio-One.

Mice. All experiments were conducted in accordance with the guidelines for care and use of animals provided by the National Institutes of Health, and protocols were approved by the Institutional Animal Care and Use Committee at the California Institute of Technology. C57BL/6 mice used for primary cultures were purchased from the Jackson Laboratory. The $\beta 3$-GFP nAChR knock-in mouse strain has been described previously (Shih et al., 2014). The Gene Expression Nervous System Atlas (GENSAT) TH-eGFP strain (Gong et al., 2003) used for RNAsequencing (RNA-Seq) studies was purchased from the Mutant Mouse Regional Resource Center (Chapel Hill, NC). The $\alpha 6$-eGFP bacterial artificial chromosome (BAC) transgenic mice used in this study possess six copies of the $\alpha 6$-eGFP BAC (Mackey et al., 2012).

Construction of $\alpha 4$-mCherry knock-in mice. The $\alpha 4$-mCherry knock-in mouse was constructed in a manner similar to the previously described $\alpha 4$-YFP knock-in mouse (Nashmi et al., 2007). Briefly, a $\alpha 4$-mCherry knock-in construct was linearized and electroporated into CJ7 mouse embryonic stem (ES) cells. Recombinant clones were selected with G418 and screened for the presence of the neo cassette and mCherry insert by a combination of PCR and automated sequence analysis. To confirm the correct position of the homologous recombination of the targeting construct within the genome and the insertion of mCherry and neo cassette, ES cells were screened by PCR and sequencing. Karyotype analysis was used to assess chromosome number. Positive clones with the highest percentage of correct number of chromosomes were selected for a subsequent round of electroporation. Clones were injected into C57BL/6 blastocysts to create chimeras. Chimeras were mated with wild-type animals, and germline transmission was established. Founder mice were mated, and colonies with $\alpha 4$-mCherry homozygous mice were established. For timed mating of $\alpha 4$-mCherry homozygous mice, genotypes were assessed by PCR analysis of tail DNA.

Mouse ventral midbrain dopaminergic cultures. Ventral midbrain cultures were obtained from embryonic day 14 (E14) mouse embryos of either sex. Embryos were extracted from timed pregnant mice. Mice were decapitated and the ventral midbrain dissected out using a standard method (Pruszak et al., 2009). Following digestion with papain (15 min at $37^{\circ} \mathrm{C}$ ), cells were separated by DNase treatment and mechanical trituration. A total of 100,000 cells, including neurons and glia, were plated in the center of poly-L-ornithine- and laminin-coated $35 \mathrm{~mm}$ glass-bottom imaging dishes. After plating, dishes were placed in a $37^{\circ} \mathrm{C}$ incubator supplemented with $5 \% \mathrm{CO}_{2}$ for $1 \mathrm{~h}$, followed by addition of $3 \mathrm{ml}$ of Neurobasal medium supplemented with B27, GlutaMAX, 1\% Hyclone equine serum, and $100 \mu \mathrm{M}$ ascorbic acid to each dish. The culture medium was exchanged at $3 \mathrm{~d}$ intervals and no antibiotics were used. With this method, we could maintain cultures of ventral midbrain neurons for 3 months containing $\geq 10 \%$ tyrosine hydroxylase positive $(\mathrm{TH}+)$ neurons. Assays described in this study were performed at 3 weeks in culture. Nicotine (200 nM) was added to the culture for 2 weeks from days 7-21 after initial plating and was replenished every $3 \mathrm{~d}$.

Mouse neuroblastoma-2a cell culture. Neuroblastoma-2a (Neuro-2a) cells were cultured using standard techniques (Xiao et al., 2011; Srinivasan et al., 2012; Henderson et al., 2014). Cells were plated by adding 90,000 cells to poly-D-lysine-coated $35 \mathrm{~mm}$ glass-bottom imaging dishes (MatTek) and cultured in a humidified incubator $\left(37^{\circ} \mathrm{C}, 95 \%\right.$ air, $5 \%$ $\mathrm{CO}_{2}$ ). Cells were transfected with $500 \mathrm{ng}$ ATF6-eGFP plasmid mixed with $250 \mu \mathrm{l}$ of Opti-MEM. Lipofectamine-2000 was separately added to $250 \mu \mathrm{l}$ of Opti-MEM. After $5 \mathrm{~min}$ at $24^{\circ} \mathrm{C}$, DNA and Lipofectamine 


\section{A}
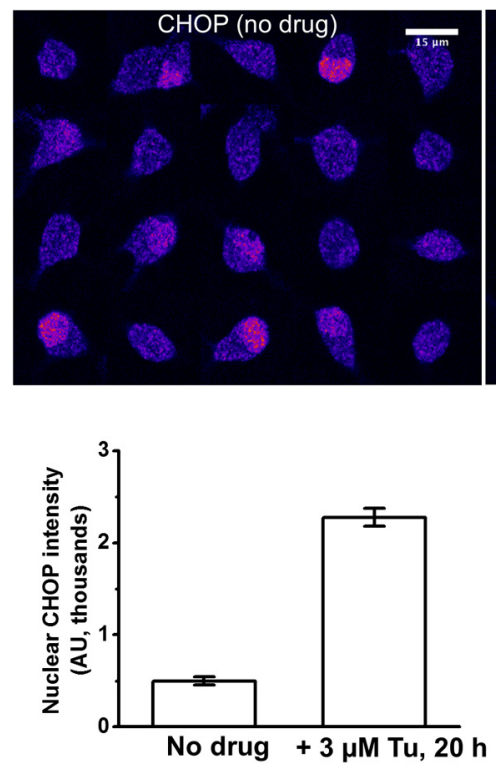
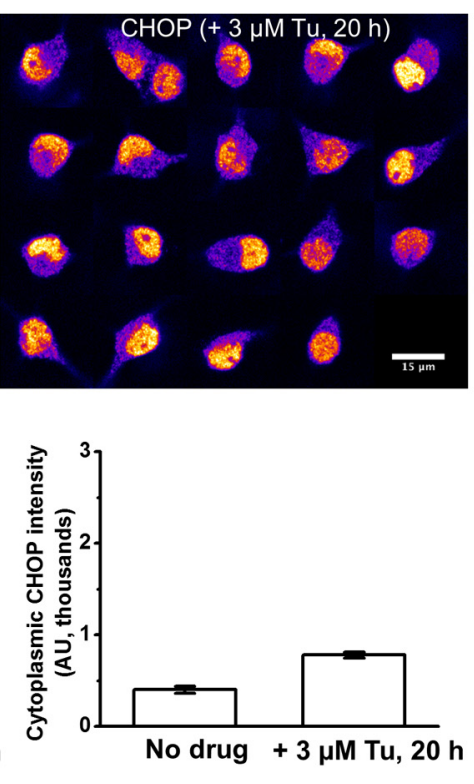
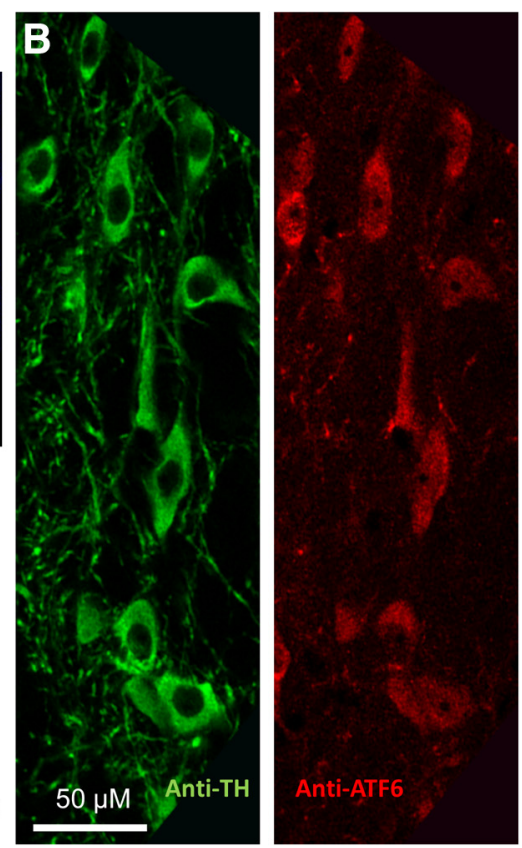

Figure 1. Validation of antibodies. A, CHOP antibody staining in WT mouse ventral midbrain cultured cells that are also positive for TH (data not shown). Left, No drug. Right, Twenty hours in 3 $\mu \mathrm{m}$ Tu. The left and right graphs show the nuclear and cytoplasmic CHOP intensity, respectively. $\boldsymbol{B}$, ATF6 antibody staining in slices from adult mouse substantia nigra. Double staining with anti-TH and anti-ATF6 shows that all DA neurons also stain for ATF6.

solutions were mixed together and incubated for $25 \mathrm{~min}$ at $24^{\circ} \mathrm{C}$. The solutions were then added to preplated Neuro-2a cells and incubated for $24 \mathrm{~h}$. After $24 \mathrm{~h}$, the Opti-MEM was removed and replaced with growth medium. One hundred nanomolar filter-sterilized nicotine or Tu was added during transfection for $48 \mathrm{~h}$ treatment (Srinivasan et al., 2012). Imaging experiments were performed in live Neuro-2a cells at $37^{\circ} \mathrm{C}$ in a stage-mounted culture dish incubator (Warner Instruments). Confocal imaging was conducted as described below (Confocal imaging and analysis). Before an imaging session, cell culture medium was replaced with extracellular solution, pH 7.4. eGFP was excited at $488 \mathrm{~nm}$. For quantification, regions of interest (ROIs) were demarcated manually using ImageJ (NIH; http://rsb.info.nih.gov/ij/).

Immunostaining. Neuron-glia cultures were fixed with $4 \%$ paraformaldehyde for $20 \mathrm{~min}$ at room temperature (RT), washed two times with PBS, and incubated with $0.01 \%$ Triton X-100 for 5 min at RT. Following two washes with PBS, cells were incubated in $10 \%$ donkey serum (DS) for $30 \mathrm{~min}$ at RT, followed by incubation with the primary antibody in $1 \%$ DS for $1 \mathrm{~h}$ at RT and constant agitation. Cells were washed three times with PBS, incubated with the secondary antibody diluted in $1 \%$ DS for $1 \mathrm{~h}$ at RT with constant agitation, and washed three times with PBS. In the case of double labeling, cells were first stained with the UPR marker or mCherry primary and secondary antibodies, followed by the TH primary and secondary antibodies. $\mathrm{TH}$ and GFP antibodies were counterstained with Alexa 488 secondary, whereas an Alexa 555 secondary antibody was used to counterstain mCherry and UPR markers.

Fluorescence and bright-field images of ventral midbrain neuron-glia cultures in Figure $2 A$ were obtained with an IX81 Olympus inverted fluorescence microscope equipped with an Andor EMCCD camera and a $20 \times$ objective.

Antibody validation. Primary antibody specificity is a crucial methodological issue in immunocytochemical experiments. We have not worked previously with $\mathrm{CHOP}$ antibodies. Many commercially available $\mathrm{CHOP}$ antibodies fail evaluations for specificity, as discovered by Haataja et al. (2008). Haataja et al. (2008) recommended verifying that a known inducer of ER stress, such as Tu, does increase the level of nuclear CHOP. We therefore performed pilot experiments with a CHOP antibody, Santa Cruz Biotechnology sc-575 (1:250 dilution), also validated by Haataja et al. (2008). After treatment with Tu $(3 \mu \mathrm{M}, 20 \mathrm{~h})$, we found robust in- creases in nuclear $\mathrm{CHOP}$, with more modest increases in cytoplasmic CHOP (Fig. 1A). This reassured us that the CHOP antibody does have the required characteristics.

We previously validated the antibodies for ATF6 (ab11909; Abcam; Srinivasan et al., 2012), GFP (A11122; Invitrogen; Henderson et al., 2014), phosphorylated eukaryotic initiation factor $2 \alpha$ (p-eIF $2 \alpha$; 5324P; Cell Signaling Technology; Srinivasan et al., 2012), and total eIF2 $\alpha$ (3597S; Cell Signaling Technology; Srinivasan et al., 2012). In the present study, the mCherry antibody (632392; Clontech) showed no signal in mice lacking mCherry-labeled $\alpha 4$ subunits (see Fig. $5 C$ ), validating this antibody.

We also confirmed that the antibodies for the three ER stress markers (p-EIF2 $\alpha$, XBP1, ATF6, and CHOP) gave robust signals in immunohistochemistry on DA $(\mathrm{TH}+)$ neurons in adult mouse substantia nigra pars compacta (Henley et al., 2013). Figure $1 B$ shows that all TH+ neurons in adult substantia nigra pars compacta display immunostaining for ATF6. These data eliminate the admittedly unlikely possibility that the signals in cultured neurons are tissue culture artifacts.

We did not independently validate the TH antibody (ab1542; Millipore, 1:1000 dilution) or the XBP1 antibody (sc-7160; Santa Cruz Biotechnology). Secondary antibodies used in this study were goat anti-rabbit Alexa 555 (catalog \#A21428; Invitrogen), goat anti-rabbit Alexa 488 (catalog \#A11034; Invitrogen), donkey anti-sheep Alexa 488 (catalog \#A11015; Invitrogen), and donkey anti-mouse Alexa 555 (cata$\log$ \#A31570; Invitrogen), and were applied at a 1:2000 dilution.

Confocal imaging and analysis. Neurons were observed with a Nikon Eclipse C1si laser scanning confocal microscope equipped with a $63 \times 1.4$ numerical aperture VC Plan Apo oil objective and a 32-anode photomultiplier array. TH-labeled neurons were excited at $488 \mathrm{~nm}$ and focused to a plane where the nucleus was largest and sharply demarcated. Alexa 488 and Alexa 555 fluorescence signals were acquired from 20 to 50 cells per dish following sequential excitation with $488 \mathrm{~nm}$ and $561 \mathrm{~nm}$ laser lines, respectively. Full emission spectra were acquired in $5 \mathrm{~nm}$ bins between 470 and $620 \mathrm{~nm}$, and the signal of each fluorophore was linearly unmixed from the raw spectral image using reference spectra from unlabeled control neurons and neurons labeled with either Alexa 488 or Alexa 555.

Image analysis used ImageJ version 1.46 or later (Abramoff et al., 2004). TH-labeled (Alexa 488) fluorescence was used to manually demarcate cytoplasmic ROIs using the ImageJ polygon drawing tool. The 

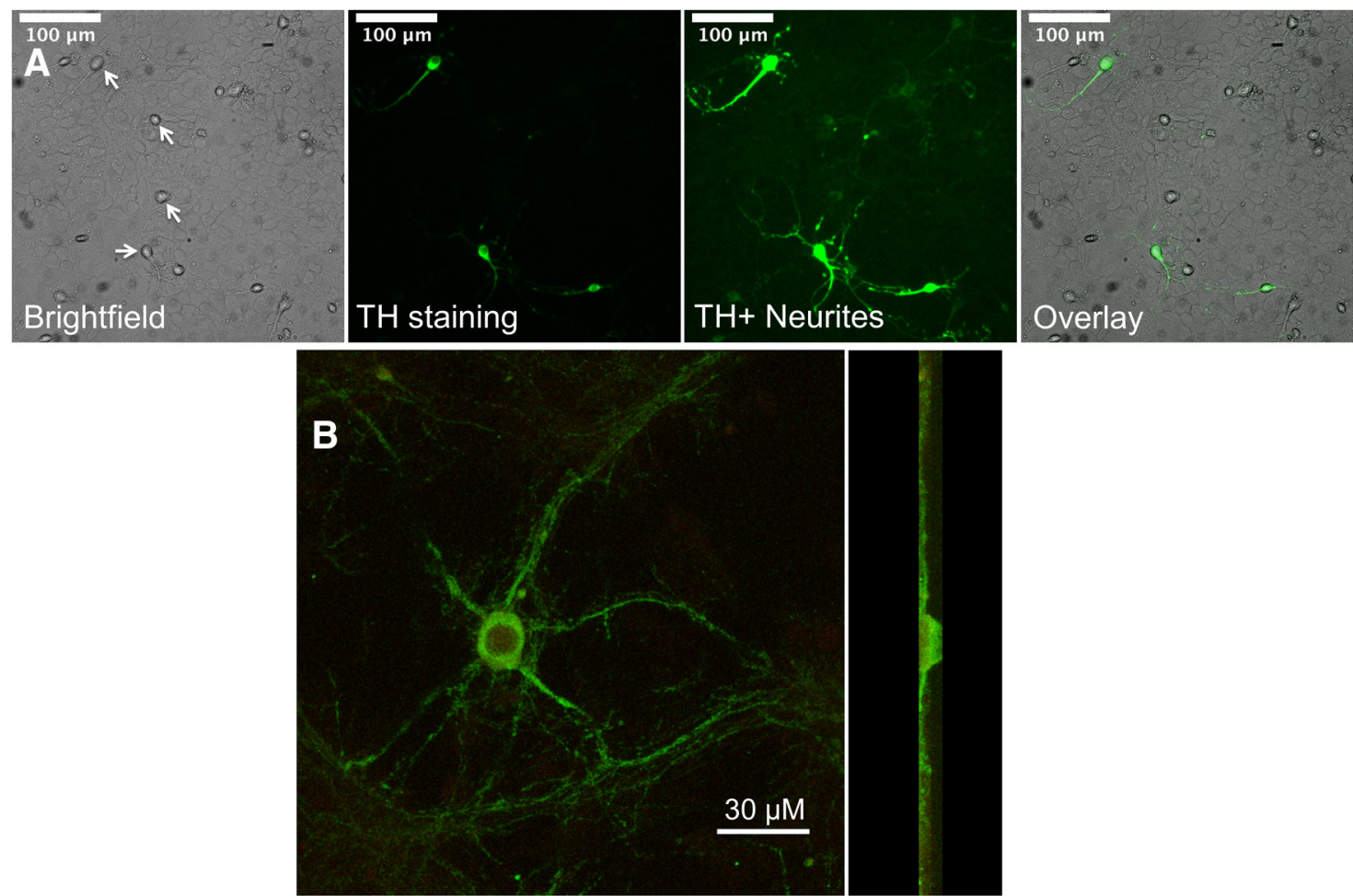

Figure 2. Cultured mouse DA neurons. $A$, Bright-field and TH-immunostained neurons from a 3-week-old WT mouse ventral midbrain culture. Left to right, Bright-field image of neurons (indicated by white arrows) growing on a glial cell monolayer, TH immunostaining of a subset of the neurons, the same image showing the extent of $\mathrm{TH}+$ processes, and a merge of $\mathrm{TH}$ immunostaining with the bright-field image. $\boldsymbol{B}$. At higher magnification, a flattened confocal stack of a TH-stained neuron. Left, Face on. Right, Side view. The processes are restricted to a plane near the coverslip and probably interdigitate with the glial cell monolayer.

absence of TH-stained fluorescence within the cell was used to manually demarcate nuclear ROIs. This process was completed individually for all imaged neurons. For every TH-labeled (Alexa 488) neuron, a UPR marker (CHOP, ATF6, etc.) was labeled with Alexa 555 fluorescence. Cytoplasmic and nuclear ROIs selected from TH labeling were applied to the Alexa 555 image of the same neuron. The ROIs were then used to calculate the UPR marker intensity as a function of Alexa 555 fluorescence. The UPR marker mean intensity was then normalized to the mean intensity of the non-nicotine control neurons that were acquired during the same imaging session.

Single cell RNA-Seq library construction from TH-eGFP mice. Ventral midbrain cultures from TH-eGFP cultures were imaged on a wide-field fluorescence microscope as described previously (Henley et al., 2013). Single cell RNA-Seq libraries were generated as described previously (Henley et al., 2013).

Electrophysiology. Glass coverslips with neuron-glia cultures were detached from imaging dishes and cut into two equal pieces, and one piece was placed in the recording chamber of an upright microscope (BX50WI; Olympus). Nicotine-free solutions were present $>1$ h before recordings. Electrophysiological signals were recorded from visually identified neurons with a MultiClamp 700B amplifier (Molecular Devices), a Digidata 1322 analog-to-digital converter (Molecular Devices), and pClamp 9.2 software (Molecular Devices). Patch pipettes were filled with solution containing the following (in $\mathrm{mm}$ ): $135 \mathrm{~K}$ gluconate, $5 \mathrm{KCl}, 5 \mathrm{EGTA}, 0.5 \mathrm{CaCl}_{2}, 10 \mathrm{HEPES}, 2 \mathrm{Mg}$ ATP, and 0.1 GTP (pH adjusted to 7.2 with Tris-base, osmolarity was adjusted to $280-300 \mathrm{mOsm}$ with sucrose). The resistance of patch pipettes was 4-8 $\mathrm{M} \Omega$. Junction potential was nulled just before forming a gigaseal. Series resistance was monitored without compensation throughout the experiment. Data were discarded if the series resistance $(10-25 \mathrm{M} \Omega)$ changed by $>20 \%$ during recordings. All recordings were done at room temperature. After achieving a gigaseal, gentle suction was used to achieve whole-cell configuration. The neuron was current clamped at $0 \mathrm{pA}$ to record spontaneous action potentials (APs), and then voltage clamped at $-50 \mathrm{mV}$ and subjected to step hyperpolarizing test pulses at $20 \mathrm{mV}$ increments to measure the presence or absence of $I_{\mathrm{h}}$. Images of some recorded neurons were captured using a Hamamatsu Orca 03G digital CCD camera (see Fig. 8).

To elicit ACh responses, $300 \mu \mathrm{M}$ ACh was dissolved in extracellular solution containing (in mM) $140 \mathrm{NaCl}, 5 \mathrm{KCl}, 2 \mathrm{CaCl}_{2}, 1 \mathrm{MgCl}_{2}, 10$ HEPES, and 10 glucose ( $320 \mathrm{mOsm}, \mathrm{pH}$ set to 7.3 with Tris-base) and puffed $(0.2 \mathrm{~s}, 20 \mathrm{psi})$ onto voltage-clamped neurons (holding potential, $-50 \mathrm{mV})$. Data were sampled at $10 \mathrm{kHz}$. For traces like those in Figure 9, data were additionally filtered at $100 \mathrm{~Hz}$. To avoid receptor desensitization by repetitive ACh application, we applied ACh at $\sim 3$ min intervals and continually perfused the recording chamber with extracellular solution (Tapper et al., 2004; Xiao et al., 2009).

Statistical analysis. Data were analyzed and graphs generated using Origin, version 7 (OriginLab), and they are presented as mean \pm SEM, where $n$ represents the number of cells studied. The statistical significance of differences was evaluated using a Student's $t$ test (without correction for multiple comparisons) with confidence levels of $p<0.001$, $p<0.01, p<0.05$, and $p \geq 0.05$ (not significant). The data in Figure 6 were analyzed with a one-way ANOVA analysis with Tukey comparisons.

\section{Results}

\section{Culture and characterization of mouse DA neurons}

To study nicotine neuroprotection in a system that emphasizes cell-delimited rather than possible circuit-based influences of chronic exposure to nicotine, we established procedures for the long-term primary culture of mouse ventral midbrain neurons (see Materials and Methods). Our 3-week-old neuron-glia ventral midbrain cultures consisted of a glial cell monolayer and midbrain neurons (Fig. 2). Ten percent or more of the neurons were $\mathrm{TH}+$ with neurites ranging from 100 to $200 \mu \mathrm{m}$ in length (Fig. 2). 

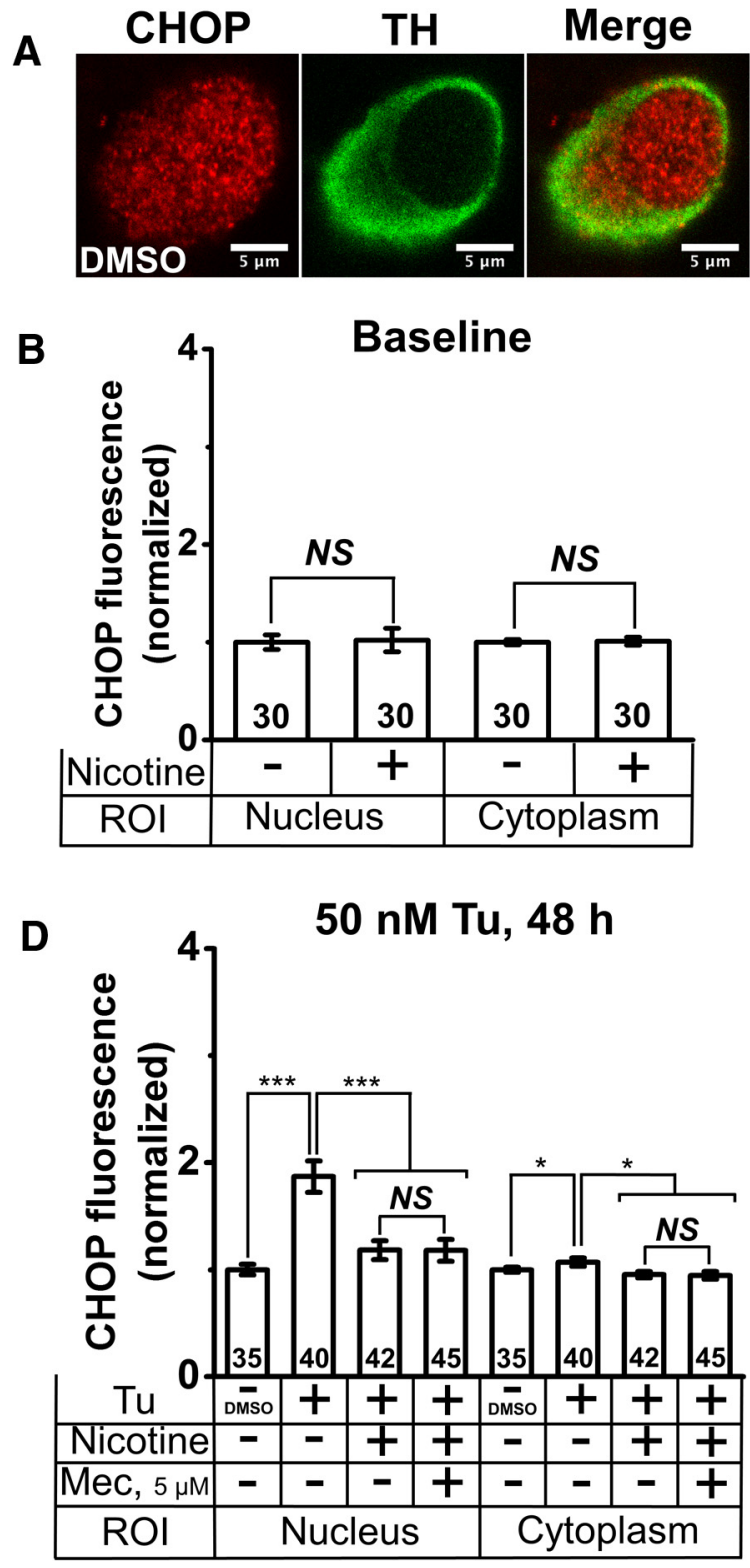
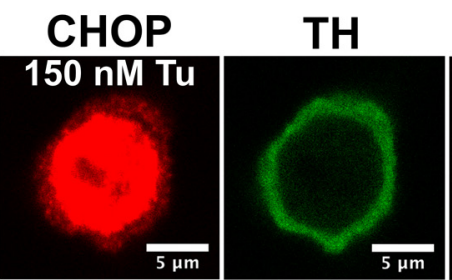

Merge
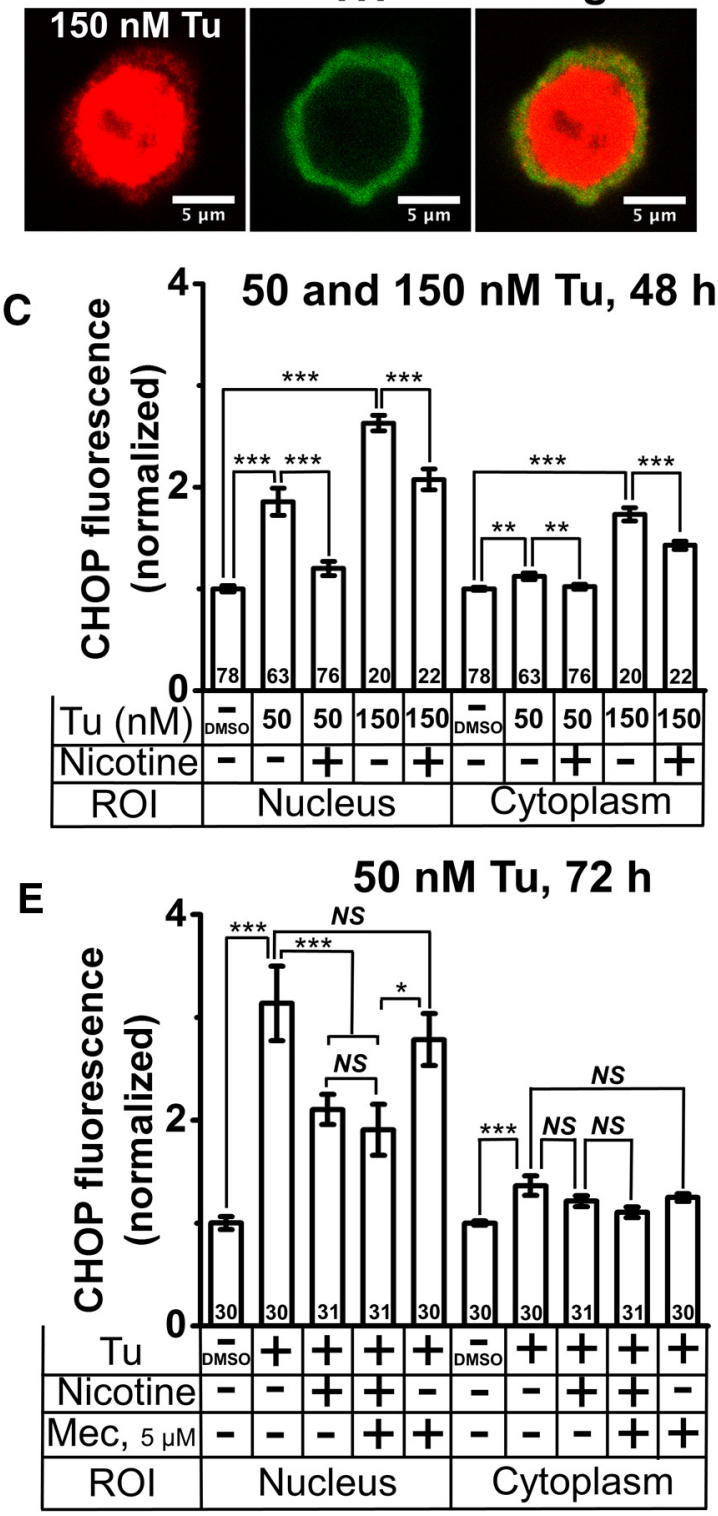

Figure 3. Nicotine inhibits Tu-induced upregulation and nuclear translocation of CHOP in cultured DA neurons. $\boldsymbol{A}$, Representative confocal images of DMSO-treated (three left panels) and 150 nM Tu-treated (three right panels) DA neurons. TH, CHOP staining, and a merged image are shown in each case. $\boldsymbol{B}$, Normalized baseline $\mathbf{C H O P}$ fluorescence with and without nicotine treatment. $\boldsymbol{C}$, Normalized CHOP fluorescence following treatment with 50 or $150 \mathrm{~nm}$ Tu with and without nicotine pretreatment. D, Normalized CHOP fluorescence following treatment with $50 \mathrm{~nm}$ Tu for $48 \mathrm{~h}$ with and without nicotine (Nic) and mecamylamine (Mec) pretreatment. $\boldsymbol{E}$, Normalized CHOP fluorescence following treatment with $50 \mathrm{~nm} \mathrm{Tu}$ for $72 \mathrm{~h}$ with and without nicotine and mecamylamine pretreatment. For all graphs, drugs applied and subcellular compartments (nucleus or cytoplasm) are shown on the $x$-axis. Nicotine ( $200 \mathrm{nm)} \mathrm{and} \mathrm{mecamylamine} \mathrm{(5} \mu \mathrm{m}$ ) were applied from $7 \mathrm{to} 21 \mathrm{~d}$ in culture; Tu was applied for $72 \mathrm{~h}$. The number of neurons imaged is shown in each bar in the graphs. Error bars are $\pm S E M$, and $p$ values are based on $S t u d e n t ' s$ two-tailed $t$ test with unequal variance. ${ }^{*} p<0.05 ;{ }^{* *} p<0.01 ;{ }^{* *} p<0.001$. NS, Not significant.

Chronic nicotine exposure suppresses upregulation and nuclear translocation of CHOP in DA neurons

We assessed the effects of chronic nicotine exposure on the proapoptotic effector, CHOP. WT DA neurons were coimmunostained with $\mathrm{TH}$ and $\mathrm{CHOP}$ antibodies. TH staining was used as a visual guide to manually demarcate the nuclear and cytoplasmic compartments of TH-positive DA neurons, and CHOP fluorescence was separately quantified in the nuclear or cytoplasmic ROIs of untreated or nicotine-treated DA neurons (200 nM nicotine from 7 to $21 \mathrm{~d}$ in culture).

Untreated DA neurons showed uniform CHOP fluorescence throughout the cell (Fig. 3A, left three panels), and exposure to nicotine alone did not alter CHOP intensity in either the nucleus or the cytoplasm (Fig. 3B). We induced prolonged and mild ER stress by incubating DA cultures with low doses of the known ER stress inducer, Tu (50 or $150 \mathrm{~nm}$ for $72 \mathrm{~h}$ ). Fifty nanomolar Tu caused a significant 1.8-fold increase of CHOP fluorescence in the nucleus of DA neurons and a small but significant increase in cytoplasmic CHOP (Fig. 3C). Pretreatment with nicotine (200 nM, from 7 to $21 \mathrm{~d}$ in culture) significantly reduced nuclear and cytoplasmic CHOP fluorescence to levels indistinguishable from baseline (Fig. 3C).

At a higher concentration of $\mathrm{Tu}(150 \mathrm{nM})$, nicotine only partially suppressed CHOP elevation. Tu caused a significant 2.8fold increase in nuclear $\mathrm{CHOP}$ and an $\sim 1.8$-fold increase in cytoplasmic CHOP (Fig. $3 A$, right three panels, $C$ ). Nicotine exposure (200 nM, 7 to $21 \mathrm{~d}$ in culture) significantly reduced $\mathrm{CHOP}$ 

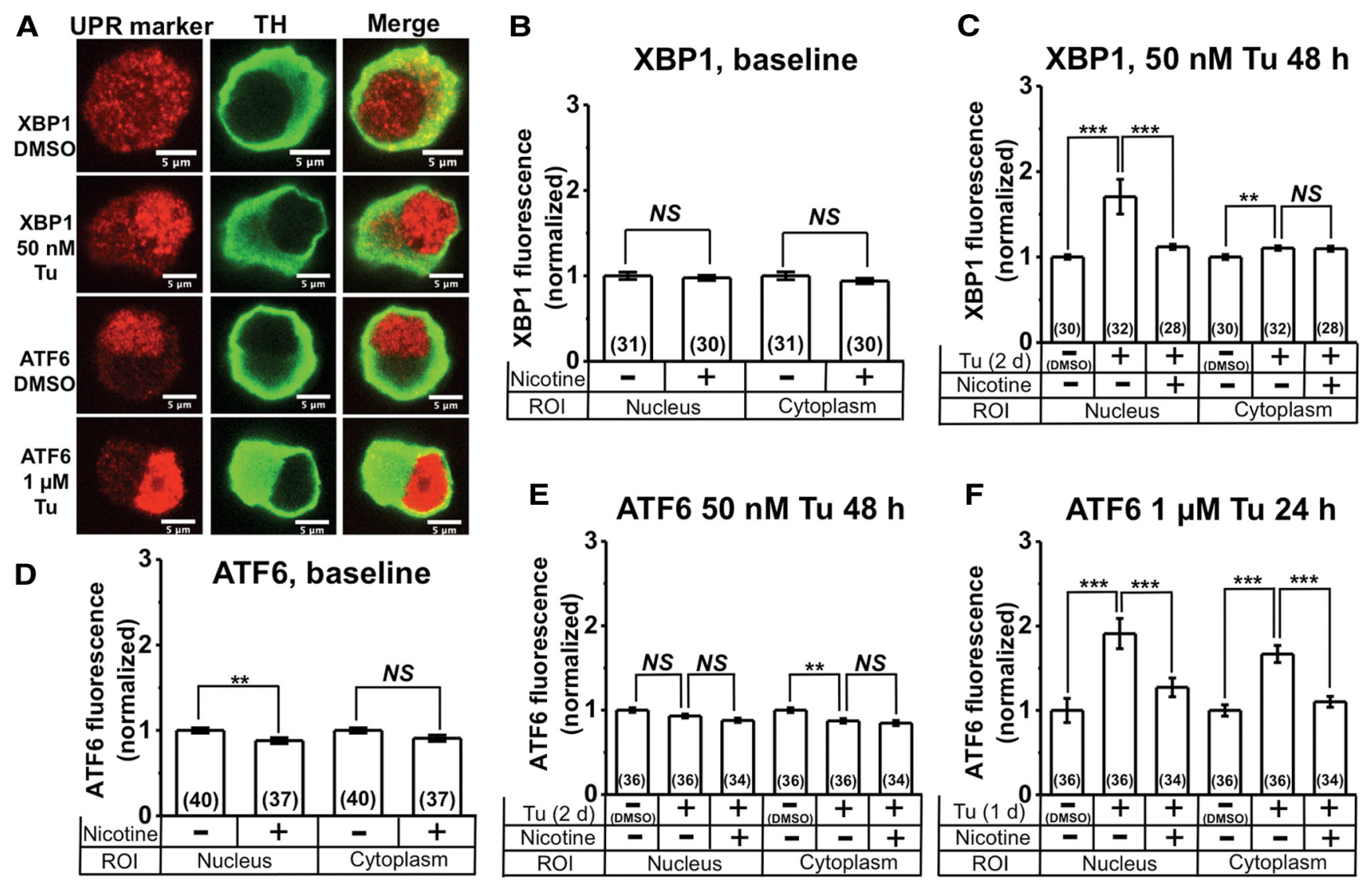

Figure 4. Nicotine inhibits Tu-induced upregulation and nuclear translocation of XBP1 and ATF6 in cultured DA neurons. $A$, Representative confocal images of DA neurons stained with either XBP1 or ATF6 plus either DMSO or Tu. The UPR marker is indicated for each row, and column labels indicate images with TH staining and merged images. $\boldsymbol{B}$, Normalized baseline XBP1 fluorescence with and without nicotine treatment. $C$, Normalized XBP1 fluorescence following treatment with $50 \mathrm{~nm} \mathrm{Tu}$, with and without nicotine pretreatment. $\boldsymbol{D}$, Normalized baseline ATF6 fluorescence with and without nicotine treatment. $\boldsymbol{E}$, Normalized ATF6 fluorescence following treatment with $50 \mathrm{~nm}$ Tu for $48 \mathrm{~h}$, with and without nicotine pretreatment. $\boldsymbol{F}$, Normalized ATF6 fluorescence following treatment with $1 \mu \mathrm{m}$ Tu for $24 \mathrm{~h}$, with and without nicotine pretreatment. For all graphs, drugs applied and subcellular compartments (nucleus or cytoplasm) are shown on the $x$-axis. Nicotine (200 $\mathrm{nm}$ ) was applied from 7 to $21 \mathrm{~d}$ in culture. The number of neurons imaged is shown in parentheses for each bar in the graphs. Error bars are \pm SEM, and $p$ values are based on Student's two-tailed $t$ test with unequal variance. ${ }^{* *} p<0.01 ;{ }^{* *} p<0.001$. NS, Not significant.

levels in the nucleus and in the cytoplasm, but to levels that were elevated with respect to baseline (Fig. 3C).

To test whether the effect of nicotine on CHOP depended on the activation of surface nAChRs, DA cultures were pretreated with either nicotine ( $200 \mathrm{~nm}$ from 7 to $21 \mathrm{~d}$ in culture) or nicotine and the nonselective $\mathrm{nAChR}$ antagonist mecamylamine $(5 \mu \mathrm{M}$ from 7 to $21 \mathrm{~d}$ in culture), and mild ER stress was induced with Tu (50 nM for 48 or $72 \mathrm{~h}$ ). Tu (50 nM) increased nuclear CHOP fluorescence by 1.8 -fold after $48 \mathrm{~h}$ (Fig. $3 \mathrm{D}$ ) and by 3.1 -fold after $72 \mathrm{~h}(E)$ of exposure. As expected, Tu also induced a small but significant increase in cytoplasmic $\mathrm{CHOP}$ fluorescence at 48 and $72 \mathrm{~h}$ time points (Fig. $3 D, E$ ), and nicotine significantly attenuated Tu-induced CHOP upregulation in the nucleus and cytoplasm of DA neurons (Fig. 3D,E). When compared to cells treated with nicotine alone, cotreatment of DA cultures with mecamylamine ( $5 \mu \mathrm{M}$ from 7 to $21 \mathrm{~d}$ in culture) and nicotine did not affect CHOP fluorescence in the nucleus or cytoplasm following exposure to $50 \mathrm{~nm}$ Tu for 48 or $72 \mathrm{~h}$ (Fig. $3 D, E$ ). In control experiments, pretreatment of DA cultures with mecamylamine alone ( $5 \mu \mathrm{M}$ from 7 to $21 \mathrm{~d}$ in culture) did not attenuate $\mathrm{Tu}$ induced CHOP upregulation in the cytoplasm or the nucleus (Fig. 3E).

These data demonstrate that nicotine attenuates CHOP upregulation and nuclear translocation in cultured DA neurons. This effect occurs at a smoking-relevant nicotine concentration that activates few plasma membrane nAChRs, as well as in the presence of a nAChR channel blocker.

\section{Chronic nicotine suppresses nuclear translocation of XBP1} and ATF6 in stressed DA neurons

Since CHOP is downstream of UPR signaling pathways, we assessed three signaling arms of the UPR triggered by ER resident stress sensors (Figs. 4, 5). These arms are (1) XBP1, which lies downstream of the ER stress sensor inositol-requiring enzyme 1 (IRE1); (2) ATF6; and (3) the protein kinase RNA-like endoplasmic reticulum kinase (PERK) pathway. The PERK pathway leads to eIF $2 \alpha$ phosphorylation.

DA neurons were costained with TH and either XBP1 or ATF6 antibodies, and nuclear and cytoplasmic fluorescence were quantified separately. Under baseline conditions, we observed a uniform fluorescence of XBP1 in the nucleus and cytoplasm of DA neurons (Fig. 4A). XBP1 fluorescence intensity in the nucleus and cytoplasm were unaffected following chronic nicotine treatment (200 nM from 7 to $21 \mathrm{~d}$ in culture; Fig. $4 B$ ). Treatment with low-dose Tu (50 nM, $48 \mathrm{~h}$ ) caused an $\sim 1.8$-fold increase in nuclear XBP1 compared to untreated controls (Fig. $4 A, C$ ) and a small but significant increase in cytoplasmic XBP1 (Fig. 4C). Pretreatment with nicotine (200 nM from 7 to $21 \mathrm{~d}$ ) inhibited the Tu-induced increase in nuclear XBP1 (Fig. 4C), but had no effect on cytoplasmic XBP1 (Fig. 4C). 

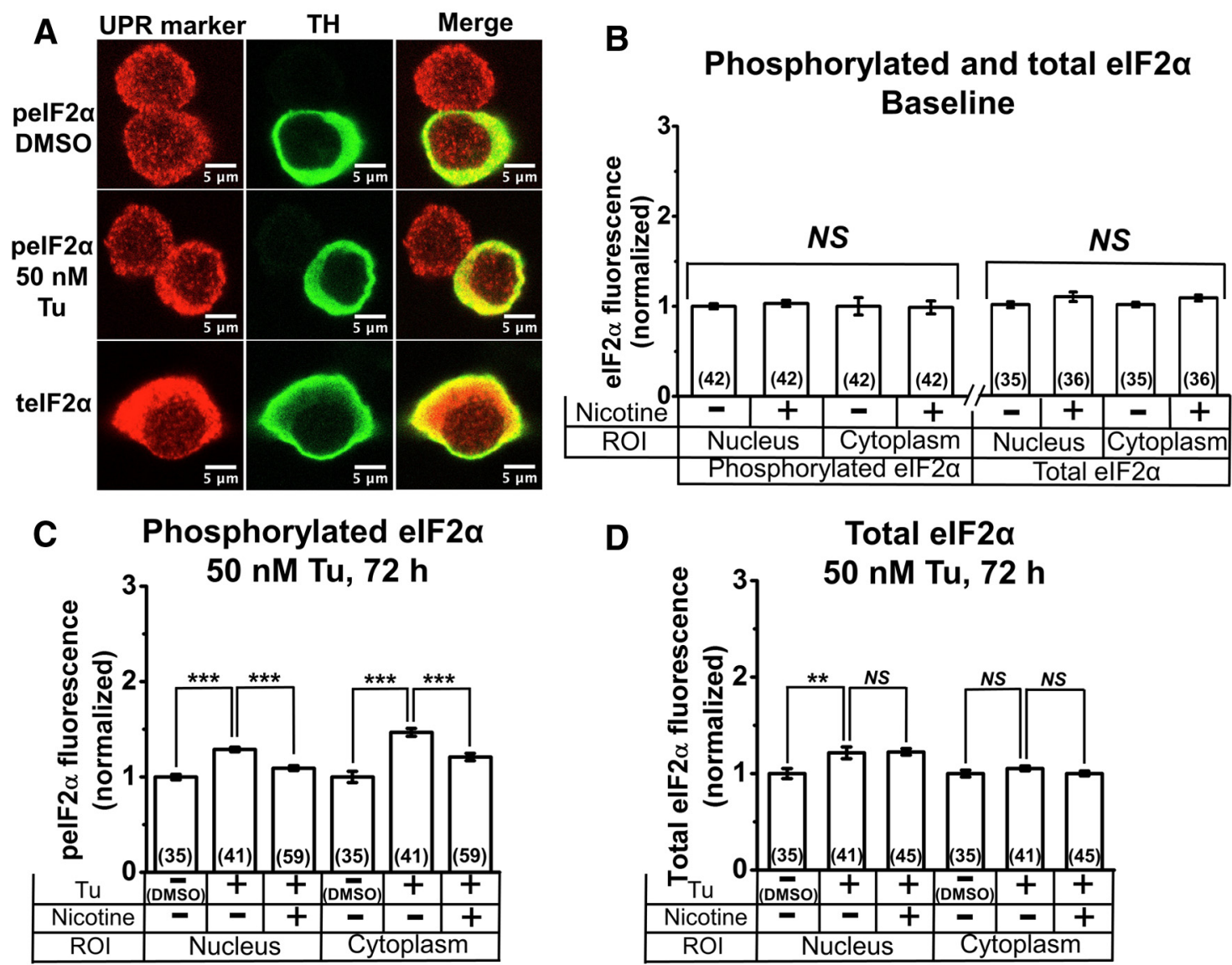

Figure 5. Nicotine inhibits Tu-induced phosphorylation of elF $2 \alpha$ in cultured DA neurons. $A$, Representative confocal images of DA neurons. Top two rows, Neurons treated with either DMSO or Tu and stained for phosphorylated elF $2 \alpha$ (pelF $2 \alpha$ ). Bottom, Neurons treated with DMSO and stained for total elF $2 \alpha$ (telF2 $\alpha$ ). Column labels indicate images with TH staining and merged images. $\boldsymbol{B}$, Normalized baseline total and phosphorylated elF $2 \alpha$ fluorescence with and without nicotine. C, Normalized phosphorylated elF $2 \alpha$ fluorescence following treatment with $50 \mathrm{~nm}$ Tu for $72 \mathrm{~h}$, with and without nicotine pretreatment. D, Normalized total elF $2 \alpha$ fluorescence following treatment with $50 \mathrm{~nm}$ Tu for $72 \mathrm{~h}$, with and without nicotine pretreatment. For all graphs, drugs applied and subcellular compartments (nucleus or cytoplasm) are shown on the $x$-axis. Nicotine $(200 \mathrm{~nm})$ was applied from 7 to $21 \mathrm{~d}$ in culture. The number of neurons imaged is shown in parentheses for each bar in the graphs. Error bars are \pm SEM, and $p$ values are based on Student's two-tailed $t$ test with unequal variance. ${ }^{* *} p<0.01 ; * * p<0.001$. NS, Not significant.

In contrast to XBP1, ATF6 showed a distinct nuclear localization of fluorescence under baseline conditions (Fig. 4A). When compared to untreated cells, nicotine ( $200 \mathrm{~nm}$ from 7 to $21 \mathrm{~d}$ in culture) significantly reduced nuclear ATF6 by $\sim 12 \%$, with no effect on cytoplasmic ATF6 fluorescence (Fig. 4D). Surprisingly, treatment of DA cultures with $50 \mathrm{~nm}$ Tu for $48 \mathrm{~h}$ failed to upregulate ATF6 fluorescence in the nucleus or the cytoplasm (Fig. 4E), and nicotine pretreatment did not affect nuclear or cytoplasmic ATF6 following $48 \mathrm{~h}$ exposure to $50 \mathrm{~nm}$ $\mathrm{Tu}$ (Fig. 4E). To induce a robust ER stress response with ATF6, we exposed DA neurons to a 20 -fold higher concentration of $\mathrm{Tu}(1 \mu \mathrm{M})$ for $48 \mathrm{~h}$. One micromolar Tu-treated DA neurons showed a significant $\sim 1.8$-fold increase in nuclear and cytoplasmic ATF6 fluorescence compared to untreated control cells (Fig. 4A,F). Pretreatment with nicotine (200 nm from 7 to $21 \mathrm{~d}$ in culture) significantly inhibited $\mathrm{Tu}$-induced upregulation of nuclear and cytoplasmic ATF6 fluorescence (Fig. 4F).

These data show that smoking-relevant concentrations of nicotine attenuate the IRE1 and ATF6 signaling pathways in cultured DA neurons. These are two arms of the UPR.

Chronic nicotine inhibits eIF2 $\alpha$ phosphorylation in Tustressed DA neurons

Because of an established role for eIF2 $\alpha$ phosphorylation in chronic ER stress and CHOP activation (Galehdar et al., 2010;
Colla et al., 2012a,b; Moreno et al., 2012; Mercado et al., 2013), we assessed the effect of chronic nicotine on total and phosphorylated eIF $2 \alpha$ in the nucleus and cytoplasm of cultured DA neurons. DA cultures were treated with nicotine (200 nM from 7 to $21 \mathrm{~d}$ in culture) and costained for either total or phosphorylated eIF2 $\alpha$. TH staining was used to identify DA neurons and to demarcate the nucleus and cytoplasm of cells (Fig. 5A). We observed phosphorylated and total eIF $2 \alpha$ fluorescence in the nucleus and cytoplasm of $\mathrm{TH}-$ and $\mathrm{TH}+$ neurons (Fig. $5 \mathrm{~A}$ ) and focused our studies on the TH+ (DA) neurons. Nicotine treatment (200 nM from 7 to $21 \mathrm{~d}$ in culture) did not affect nuclear and cytoplasmic levels of either phosphorylated or total eIF $2 \alpha$ in $\mathrm{TH}+$ neurons (Fig. $5 B$ ). Exposure of DA cultures to $50 \mathrm{~nm} \mathrm{Tu}$ for $72 \mathrm{~h}$ caused a significant increase in phosphorylated eIF $2 \alpha$ fluorescence in the cell nucleus and cytoplasm of $\mathrm{TH}+$ neurons (Fig. $5 C$ ), whereas nicotine pretreatment ( $200 \mathrm{~nm}$ from 7 to $21 \mathrm{~d}$ in culture) significantly inhibited the upregulation of phosphorylated eIF $2 \alpha$ in the cell nucleus and cytoplasm of TH+ neurons (Fig. 5C).

To assess whether the effects of nicotine on eIF $2 \alpha$ were due to a specific inhibition of phosphorylation or due to inhibition of total eIF2 $\alpha$ upregulation, we studied TH+ (DA) neurons coimmunostained for total eIF2 $\alpha$ (Fig. $5 A$ ). Similar to phosphorylated eIF $2 \alpha$, total eIF $2 \alpha$ staining was observed in the nucleus and cytoplasm of $\mathrm{TH}+$ neurons with cytoplasmic staining being $\sim 10$ - 
fold brighter than nuclear fluorescence (Fig. 5A). Tu (50 nM, $72 \mathrm{~h}$ ) caused a significant increase in total eIF $2 \alpha$ within the cell nucleus but failed to increase the cytoplasmic content of total eIF2 $\alpha$ (Fig. 5D). Compared to Tu-treated cells, nicotine pretreatment $(200 \mathrm{~nm}$ from 7 to $21 \mathrm{~d}$ in culture) did not affect total eIF $2 \alpha$ levels in either the nucleus or the cytoplasm (Fig. 5D).

These data show that chronic nicotine suppresses eIF $2 \alpha$ phosphorylation in Tustressed DA neurons in culture. This is the third arm of the UPR pathway.

\section{nAChRs are required for nicotine-}

induced reduction in ER stress markers

We used cultured Neuro-2a cells to determine whether the presence of nAChRs was required for nicotine-induced reduction in ER stress markers. We showed previously that Neuro-2a cells transiently transfected with $\alpha 4 \beta 2 \mathrm{nAChRs}$ exhibit a reduction in ATF6 nuclear translocation following long-term treatment with 100 nM nicotine (Srinivasan et al., 2012). We have now studied Neuro-2a cells transfected with only ATF6-eGFP to determine how ATF6 nuclear translocation, initiated by $100 \mathrm{nM} \mathrm{Tu}$, is altered by longterm nicotine treatment (Fig. 6). We observed that without nAChRs present, nicotine does not reduce ATF6 nuclear translocation.

The Neuro-2a cell experiments also provided an opportunity for pilot experiments on the omission of expression of either subunit alone. Neuro-2a cells transfected with $\alpha 4$-mCherry subunits alone displayed 1.25-fold $(p<0.05)$ elevation of ATF6 nuclear translocation, versus transfection with $\beta 2$ alone. This shows that unassembled $\alpha 4$ subunits, by themselves, evoke more ER stress than do unassembled $\beta 2$ subunits, even though either subunit is eventually degraded in the absence of the partner subunit (Whiteaker et al., 2006). These observations are consistent with the observation that cells efficiently ubiquitinate, then proteolytically degrade, $\beta 2$ subunits (Rezvani et al., 2010). In neither case ( $\alpha 4$ alone nor $\beta 2$ alone) was the level of ER stress significantly changed by incubation with nicotine, an unsurprising result because intact $\alpha / \beta$ subunit interfaces are required for nicotine binding. We therefore reasoned that $\beta 2$-subunit knock-out cultures would contain unassembled $\alpha 4$ and/or $\alpha 6$ subunits, producing an artificially high level of ER stress, unsuitable for our experiments.

We also reasoned that single $\alpha 4$ or $\alpha 6$ subunit knock-outs would produce compensatory assembly of $\beta 2^{*} \mathrm{nAChRs}$ with the remaining subunit, and/or changes in the level of $\alpha 4 \alpha 6 \beta 2$ subunits (Zoli et al., 2002; Champtiaux et al., 2003), further complicating the interpretation. We therefore generated and maintained a mouse strain that was homozygous null for both $\alpha 4$ and $\alpha 6$ nAChRs. We attempted to study embryonic cultures from these mice. However, litters were rather small, vitiating systematic studies like those that we conducted on WT mice.

Thus, we cannot say whether the ER stress reduction by nicotine depends most on $\alpha 4 \beta 2^{\star}$ or $\alpha 6 \beta 2^{\star}$ nAChRs. Previous data in transfected cell lines shows that nicotine exposure increases the number of ER exit sites for both $\alpha 4 \beta 2$ and $\alpha 6 \beta 2 \beta 3 \mathrm{nAChRs,} \mathrm{and}$

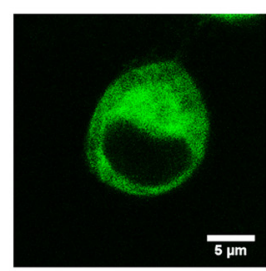

Nicotine

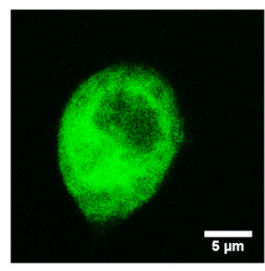

Tunicamycin

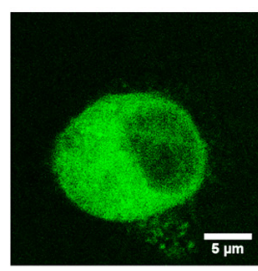

Tunicamycin Nicotine

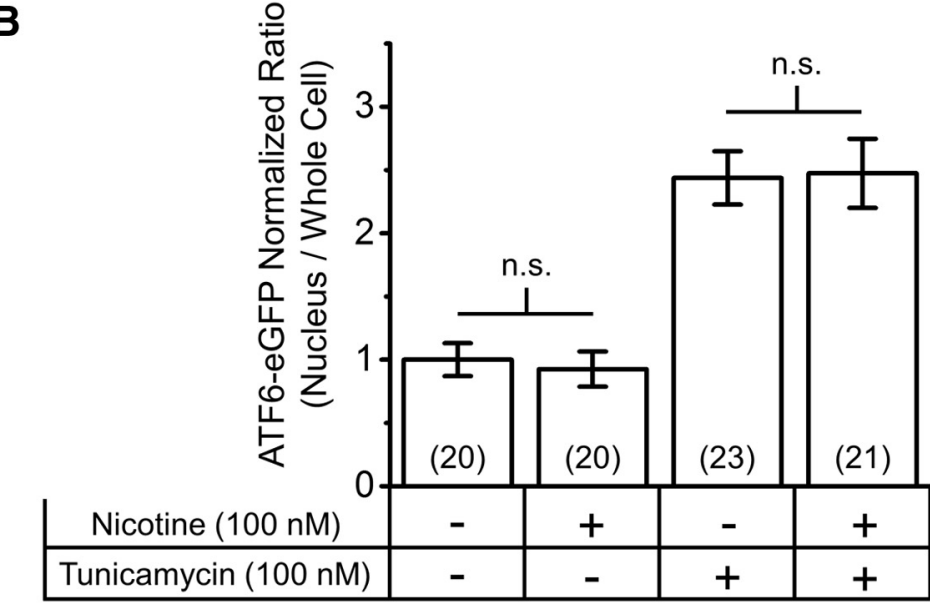

Figure 6. In Neuro-2a cells not expressing nAChRs, nicotine induced no significant changes in nuclear versus cytoplasmic calization of ATF6. $\boldsymbol{A}$, Representative confocal images of Neuro-2a cells transfected alone with ATF6-eGFP were treated with no drug, nicotine (100 nm), Tu (100 nm), or nicotine with Tu. $\boldsymbol{B}$, Normalized ATF6-eGFP nuclear translocation. These data were analyzed with a one-way ANOVA and Tukey comparisons. n.S., Not significant.

this metric seems to correlate well with reduction of ER stress (Srinivasan et al., 2011; Henderson et al., 2014).

\section{Cultured DA neurons express $\alpha 4^{*}, \alpha 6^{\star}$, and $\beta 3^{\star}$ nAChR subunits}

Midbrain DA neurons robustly express several nAChR subunits in vivo (Schwartz et al., 1984; Clarke and Pert, 1985; Zoli et al., 2002; Champtiaux et al., 2003); however the expression of nAChRs in cultured DA neurons has not been characterized. We used midbrain cultures from homozygous $\alpha 4$-mCherry knock-in and WT mice to assess $\alpha 4 \mathrm{nAChR}$ subunit expression in DA cultures. Compared to WT cultures, we observed a significant $\sim 1$.8-fold increase in direct mCherry fluorescence within the somata of $\mathrm{TH}+$ neurons at 5 and $10 \mathrm{~d}$ in culture (Fig. $7 \mathrm{~A}, \mathrm{~B}$ ). At $20 \mathrm{~d}$ in culture, there was a further $\sim 30 \%$ increase of $\alpha 4$ mCherry fluorescence in $\mathrm{TH}+$ neurons (Fig. $7 B$ ), and $99 \%$ of $\mathrm{TH}+$ neurons showed $\alpha 4$-mCherry fluorescence. To enhance the detection of mCherry signals, we labeled 3-week-old $\alpha 4$ mCherry knock-in and WT cultures with mCherry primary and Alexa 555 secondary antibodies. Using this method, we observed $\alpha 4$-mCherry fluorescence in a subset of TH + neurites from $\alpha 4$ mCherry knock-in mice, whereas WT mice showed no signal in $\mathrm{TH}+$ neurons (Fig. 7C). TH+ neurons stained with mCherry antibody showed an approximately fivefold greater mCherry fluorescence compared to neurons from WT cultures (Fig. 7D). In addition, $\mathrm{TH}+$ neurons showed a significant $\sim 2.6$-fold greater $\alpha 4$-mCherry fluorescence compared to $\mathrm{TH}-$ neurons from the same cultures (Fig. 7D). This ratio is consistent with previous reports that DA neurons express higher levels of $\alpha 4^{*}$ nAChRs than GABAergic neurons in midbrain slices (Nashmi et al., 2007).

Previous work showed that $\alpha 6^{\star} \mathrm{nAChRs}$ are expressed in adult mouse DA neurons, but not in GABAergic neurons (Zoli et al., 2002; Champtiaux et al., 2003; Drenan et al., 2008; Mackey et al., 2012), 

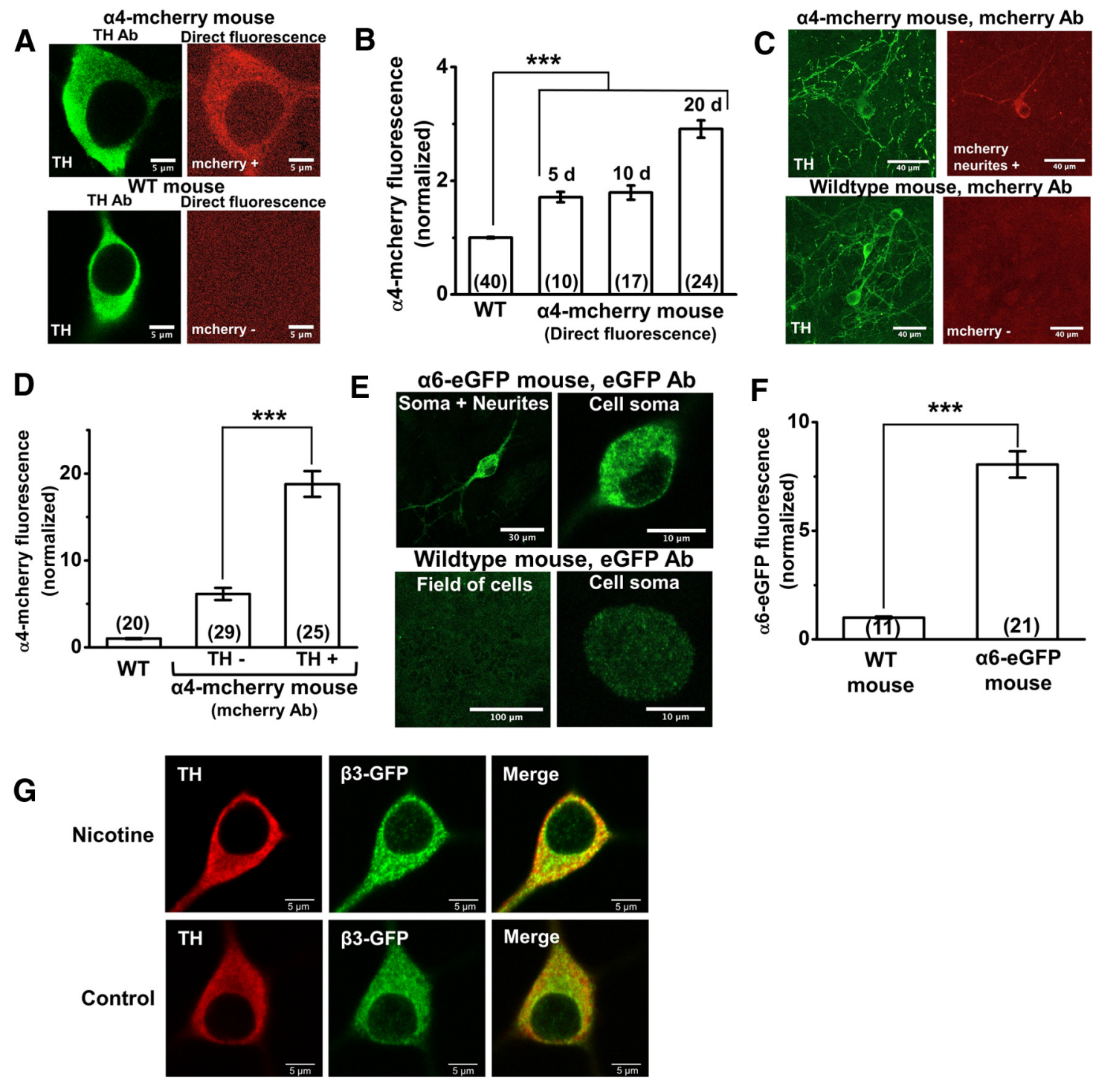

Figure 7. Cultured mouse DA neurons express endogenous nAChR proteins. $A$, Representative confocal images of neurons from an $\alpha 4$-mCherry knock-in mouse (two top panels) and WT mouse (two bottom panels) immunostained for TH (two left panels) and imaged for direct mCherry fluorescence (two right panels). $\boldsymbol{B}$, Normalized direct mCherry fluorescence from an $\alpha 4$-mCherry knock-in mouse after 5, 10, or $20 \mathrm{~d}$ in culture compared to background fluorescence from a WT mouse. C, Representative confocal images of $\alpha 4$-mCherry knock-in mouse (two top panels) and WT mouse (two bottom panels) immunostained for TH and mCherry, showing the presence of $\alpha 4$-mCherry fluorescence in a subset of TH + neurites. $\boldsymbol{D}$, Graph comparing mCherry fluorescence in TH - and TH + neurons from an $\alpha 4$-mCherry knock-in mouse after immunostaining with TH and mCherry antibodies. A WT mouse was also imaged to measure background mCherry staining. $E$, Representative confocal images of neurons from an $\alpha 6$-eGFP transgenic mouse (two top panels) and WT mouse (two bottom panels) immunostained for eGFP. The top left panel shows an eGFP + neuron with $\alpha 6$-eGFP in the neurites, and the top right panel shows is a digital zoom of the eGFP + cell body from the same neuron. Neurons from WT mice (bottom two panels) show nonspecific eGFP staining. $F$, Graph comparing eGFP fluorescence from $\alpha 6$-eGFP transgenic mice to background eGFP staining in WT mice. Scale bars are indicated for each image. The number of neurons imaged is shown in parentheses for each bar in the graphs. Error bars are \pm SEM, and $p$ values are based on Student's two-tailed $t$ test with unequal variance. ${ }^{* * *} p<0.001$. G, Immunostaining showed that $94 \%$ of $\beta 3$-GFP-positive neurons were TH positive (Fig. 6G). Nicotine ( $200 \mathrm{~nm}$ ) was applied from days 7 to 21 in the nicotine-treated cultures. The number of DA neurons (TH + and $\beta 3-G F P+)$ observed in culture did not significantly change after nicotine treatment.

and this is confirmed by the RNA-Seq data presented in Table 1 (Trapnell et al., 2012); but it was important to know whether the cultured DA neurons expressed the $\alpha 6$ subunit protein. We used $\alpha 6$-eGFP BAC transgenic mice (Mackey et al., 2012) to assess $\alpha 6^{*}$ nAChR subunit expression in cultured DA neurons. The level of $\alpha 6$ fluorescence in DA neurons was lower than the $\alpha 4$ signals, probably because the embryonic cultures came from heterozygous $\alpha 6$-eGFP crosses. (Attempts to generate homozygous $\alpha 6$-eGFP mice were unsuccessful.) Therefore, we amplified the $\alpha 6$-eGFP fluorescence by staining 3-week-old WT and $\alpha 6$-eGFP transgenic mouse cultures with GFP primary and Alexa 488 secondary antibodies. eGFP immunofluorescence signals were observed in the cell somata and neurites of midbrain neurons from $\alpha 6$-eGFP mouse cultures, whereas
WT neurons showed a nonspecific background staining (Fig. 7E). The eGFP immunofluorescence was approximately eightfold greater than the nonspecific staining of WT neurons (Fig. $7 F$ ). Thus, cultured DA neurons express $\mathrm{AAChR}$ subunits that traffic along neuronal processes, with robust nAChR expression levels achieved at 3 weeks in culture.

The $\alpha 6$ and $\beta 3 \mathrm{nAChR}$ subunit genes are adjacent, and many $\alpha 6^{\star}$ nAChRs also contain the $\beta 3$ subunit. We cultured $\beta 3$-GFP mouse ventral midbrain neurons to assess $\beta 3^{*}$ nAChR subunit expression in DA cultures. Immunostaining showed that $94 \%$ of $\beta 3$-GFP-positive neurons were TH positive (Fig. $7 G$ ). These data confirm the presence of the $\beta 3 \mathrm{nAChR}$ subunit in DA neurons at $21 \mathrm{~d}$. 
Table 1. Dopamine related and $n A C h R$ gene transcripts in DA neurons at day 21 in ventral midbrain cultures

\begin{tabular}{lll}
\hline & $\begin{array}{l}\text { TH-eGFP DA single } \\
\text { cells, } n=7\end{array}$ & $\begin{array}{l}\text { WT GABAergic single } \\
\text { cells, } n=7 \\
\text { FPKM }\end{array}$ \\
\hline TH & FPKM & 1.18 \\
DDC & 13470 & 0.84 \\
slc6a3/DAT & 1540.3 & 0.47 \\
Drd2 & 572.2 & 0.1 \\
chrna6 $(\alpha 6)$ & 33.7 & 0.07 \\
chrna4 $(\alpha 4)$ & 229.6 & 26.35 \\
chrnb2 $(\beta 2)$ & 20.9 & 17.26 \\
chrnb3 $(\beta 3)$ & 9.1 & 0.03 \\
Gad1 & 75.3 & 959 \\
Htr3A & 0.11 & 0.64 \\
Htr3B & 0 & 0
\end{tabular}

RNA-Seq data for TH-eGFP and negative neurons are shown. Single cells were harvested on culture day 21 by aspirating a single neuron from primary midbrain cultures into a glass pipette. The resultant mRNAs were reverse transcribed and amplified to construct a single-neuron high-yield cDNA sequencing library. RNA-Seq data show that DA neurons had high levels of DA-related gene transcripts, including TH, dopa decarboxylase (DDC), dopamine transporter DAT (slc6a3), and nAChR transcripts. However, these cells had low levels of the GABAergic marker gene glutamic acid decarboxylase 1 (Gad1) and the serotonin $5-H T 3$ receptor $A$ and $B$ subunits ( $H$ tr $3 A$ and $\mathrm{Htr3B}$ ). GABAergic neurons have low to no levels of DA-related gene transcripts, chrna6, chrnb3, and $\mathrm{Htr} 3 \mathrm{~A} / \mathrm{B}$, but have high levels of Gad1. RNA-Seq (Cuffdiff) data (Trapnell et al., 2012) are shown for dopamine-related, GABAergic, nicotinic receptor, and serotonin transcripts.

Additionally, no significant difference was observed in the number of DA neurons (as determined by $\mathrm{TH}$ staining) present in control-treated versus nicotine-treated WT midbrain cultures. Nicotine-treated cultures had no significant increase in WT DA neurons compared to control cultures.

The $\alpha 4$-mCherry knock-in, $\beta 3$-GFP knock-in, and $\alpha 6$-eGFP BAC transgenic mouse lines thus served their purpose of identifying some $\mathrm{nAChR}$ subunits in $\mathrm{TH}+$ neurons. These lines were not used for the electrophysiological experiments described in Figure 9.

\section{Cultured DA neurons express several DA-related mRNAs}

In addition to the presence of $\mathrm{nAChR}$ receptor subunit proteins, we asked which DA-related genes are expressed in the $\mathrm{TH}+$ neurons. We previously developed methods to obtain RNA-Seq data from single neurons in our ventral midbrain cultures (Henley et al., 2013). To extend the usefulness of such data, we cultured ventral midbrain from BAC transgenic mice driving TH-eGFP from the TH promoter, and we performed single-cell RNA-Seq on eGFP-labeled neurons. We found coexpression of TH and other DA-related gene transcripts, including dopa decarboxylase, the dopamine transporter DAT (slc6a3), and the dopamine D2 receptor, in addition to $\alpha 4, \alpha 6, \beta 2$, and $\beta 3 \mathrm{nAChR}$ subunit mRNAs, in $100 \%$ of the TH-eGFP cells analyzed (Table 1 ). At the single-cell level, the population of TH-positive neurons is congruent with the population of neurons expressing other DArelated genes.

This congruence prompted us to analyze other aspects of gene expression in the TH-eGFP neurons. Many neuronal cell types express the $\alpha 7 \mathrm{nAChR}$ subunit. $\alpha 7$ mRNA was expressed at $>1$ fragments per kilobase per million mapped reads (FPKM; at 16.14 FPKM) in only one of the seven TH-eGFP cells analyzed.

Hyperpolarization-activated cyclic nucleotide-gated (HCN) cation channels are encoded by the Hcn1-4 gene family. These channels conduct an inward, excitatory current, $I_{\mathrm{h}}$, acting as a pacemaker current to initiate rhythmic firing, dampen dendritic excitability, and regulate presynaptic neurotransmitter release (He et al., 2014). Although the presence or absence of $I_{\mathrm{h}}$ current has been used widely to distinguish DA from non-DA neurons in the midbrain, we asked whether the presence of HCN channel transcripts are an absolute identifier of cultured DA neurons. Our RNA-Seq data show that four of the seven single DA neurons, grown for $21 \mathrm{~d}$ in culture, had $\mathrm{Hcn} 3$ gene transcript levels of $>1$ FPKM. Only one of the seven GABAergic single cells had $\mathrm{Hcn} 3$ gene transcripts at $>1$ FPKM. One of the remaining TH-eGFP single cell libraries contained the Hcn 4 transcript at 1 FPKM. RNA-Seq data showed that Hcn1 and Hcn2 gene transcripts were detected at 0 or $<1$ FPKM in all of the DA and GABAergic neurons. In summary, five of the seven DA neurons, but only one GABAergic neuron, contained Hcn transcripts at $\geq 1$ FPKM. These data indicate that the Hcn 3 transcript may be a marker for, but not an absolute identifier of, DA neurons grown for $21 \mathrm{~d}$ in culture.

\section{nAChRs in cultured DA neurons functionally upregulate with chronic nicotine}

Cells morphologically identified as neurons were patch clamped (Fig. 8A), and spontaneous APs were recorded in current-clamp mode. We observed two spontaneous firing rates: 1 to $4 \mathrm{~Hz}$, often associated with DA neurons, and $\sim 10 \mathrm{~Hz}$, often associated with GABAergic interneurons (Fig. 8B). Neurons firing at 1 to $4 \mathrm{~Hz}$ displayed $I_{\mathrm{h}}$ in response to $-20 \mathrm{mV}$ hyperpolarizing steps, whereas $I_{\mathrm{h}}$ was not observed in neurons with a $\sim 10 \mathrm{~Hz}$ firing rate (Fig. 8B). A study by Chieng et al. (2011) concluded that $I_{\mathrm{h}}$ currents can strengthen the classification, but are not sufficient to reliably classify DA neurons. The RNA-Seq data presented above confirm this ambiguity.

Previous studies (Chieng et al., 2011) suggest that the most reliable electrophysiological criterion for DA neurons is the duration of the AP waveform. This finding also holds for neurons in the ventral tegmentum (Ford et al., 2006). The width of APs in our putative cultured DA neurons was 40 to $50 \%$ greater than GABAergic APs (Fig. 8C). The presence of TH as observed in our immunocytochemistry studies (Fig. 1), spontaneous firing at 1 to $4 \mathrm{~Hz}$, broad APs, and $I_{\mathrm{h}}$ currents (Drenan et al., 2008) suggest the presence of DA neurons in the ventral midbrain cultures.

We assessed whether the nAChR subunits expressed by cultured WT DA neurons form functional nAChRs. Neurons from 3-week-old WT ventral midbrain cultures were patch clamped and assigned to putative DA versus GABAergic phenotypes based on spontaneous firing rates and the presence or absence of $I_{\mathrm{h}}$. A $200 \mathrm{~ms}$ puff of $300 \mu \mathrm{M}$ ACh elicited inward currents in 9 of 12 identified putative DA neurons (Fig. $9 A$, black trace). The decay of the waveforms was probably shaped by both desensitization and diffusion of the ACh. In preliminary experiments on untreated cultures, we found that $60 \%$ of the ACh response was blocked by exposure to $\alpha$-conotoxin (CTX) MII ( $80 \mathrm{~nm}$ ). This is greater than the $\alpha$-conotoxin MII fraction in adult DA neurons (Xiao et al., 2009). In contrast, only two of seven (28\%) GABAergic neurons responded to ACh (Fig. 9B); the responses were too small and too rare for systematic study.

We tested whether chronic nicotine exposure functionally upregulates native $\mathrm{nAChRs}$ in putative DA neurons. We chose the smoking-relevant nicotine dose of $200 \mathrm{~nm}$ (Matta et al., 2007) used for ER stress experiments reported above; we exposed ventral midbrain neurons to nicotine from days 7 to 21 in culture. Responses to $200 \mathrm{~ms}$ puffs of $300 \mu \mathrm{M}$ ACh were recorded (Fig. $9 A)$. Chronic low-dose nicotine exposure caused a significant 2.4-fold increase in ACh current amplitudes $(p<0.05)$ when compared to untreated cells (Fig. $9 A, C$ ). The $\alpha 6^{*}$-selective antagonist $\alpha$-conotoxin MII revealed that $\alpha 4$ (non- $\alpha 6)^{*}$ nAChRs in 
A

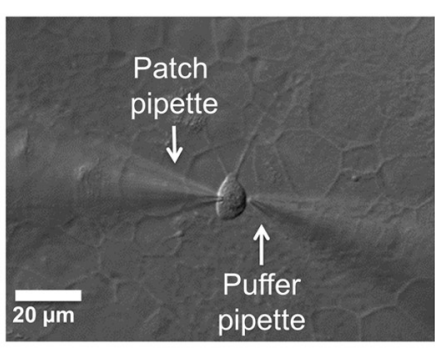

C

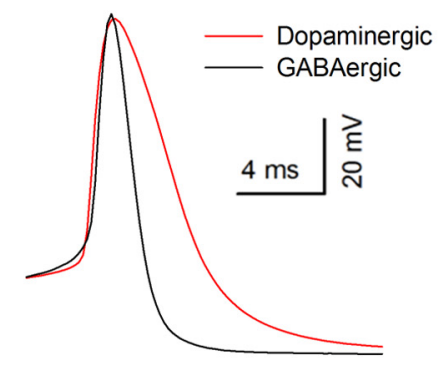

Action potential waveforms
B

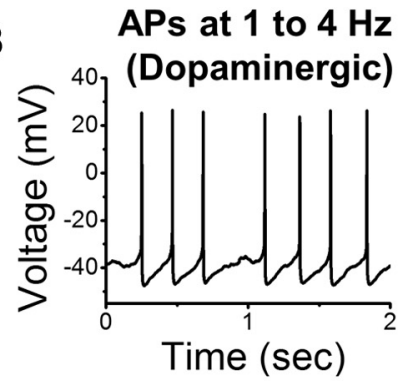

APs at $\sim 10 \mathrm{~Hz}$

(GABAergic)

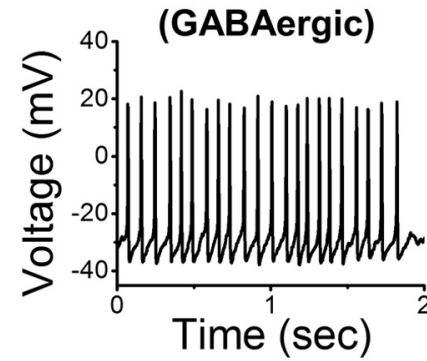

With $I_{h}$

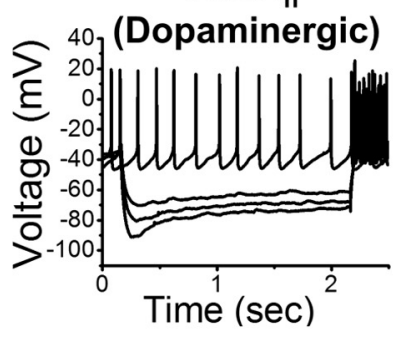

No $I_{h}$ (GABAergic)

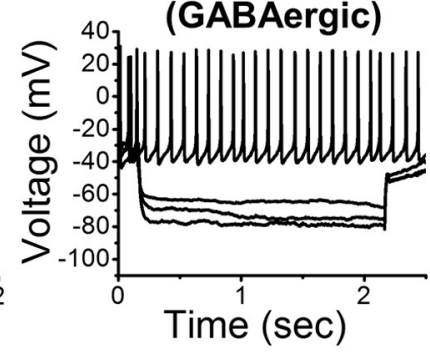

Figure 8. Electrophysiological characterization of mouse DA neurons. $A$, Representative image of a 3-week-old cultured mouse ventral midbrain neuron patch clamped for whole-cell recordings. The patch and puffer pipettes are shown. $\boldsymbol{B}$, Two left graphs show spontaneous APs in current-clamped putative dopaminergic and GABAergic neurons. Two right-hand graphs show the presence (putative dopaminergic) or absence (GABAergic) of $I_{\mathrm{h}}$ following successive $-20 \mathrm{mV}$ hyperpolarizing steps. $C$, Average APs of cultured putative dopaminergic and GABAergic neurons are superimposed for a comparison of the spike width. The putative dopaminergic neuron AP is $\sim 40 \%$ broader than the GABAergic AP.

A DA neurons

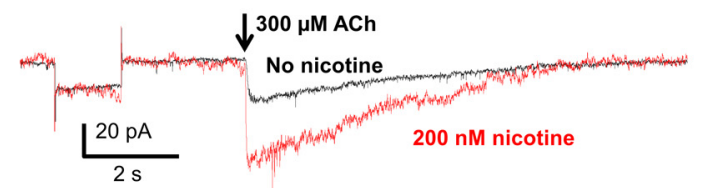

B

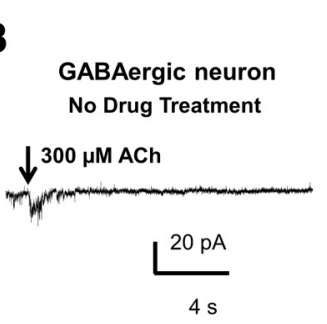

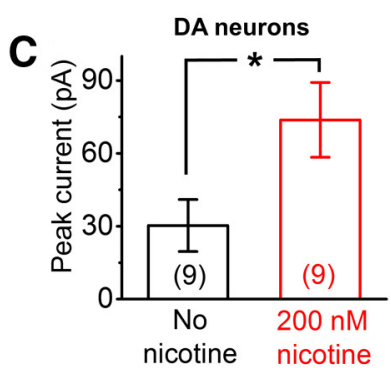

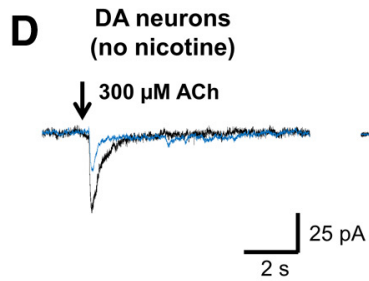

E DA neurons
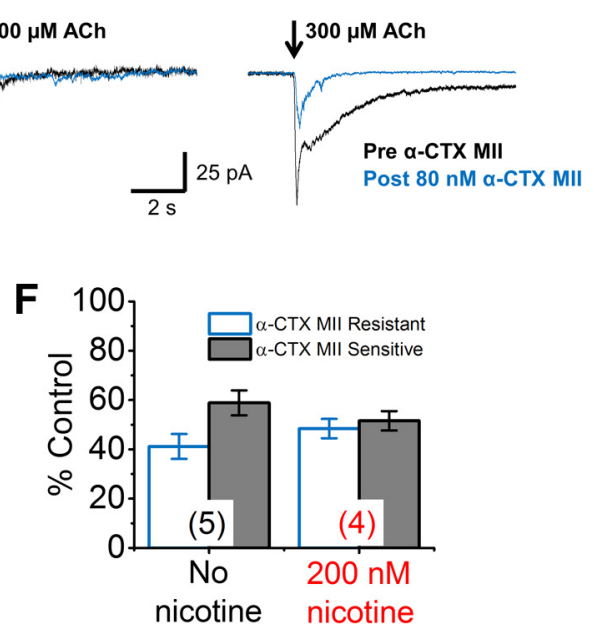

Figure 9. Endogenously expressed nAChRs in cultured mouse putative DA neurons are functional and upregulate with chronic nicotine. A, Average waveforms of $300 \mu \mathrm{m} A C h-e v 0 k e d$ currents from single trials in each of nine cultured putative DA neurons belonging to either untreated or nicotine treated groups (all neurons with holding currents $<250 \mathrm{pA}$ are included in the average). ACh pulse, $200 \mathrm{~ms}$. Black trace, Neurons without nicotine pretreatment; red trace, neurons treated with $200 \mathrm{~nm}$ nicotine from 7 to $21 \mathrm{~d}$ in culture. Average holding currents were -104 and $-85 \mathrm{pA}$ (saline- and nicotine-treated, respectively). The traces include a $5 \mathrm{mV}$ hyperpolarizing test pulse, showing that the neurons have roughly equal average input resistance of $0.3 \mathrm{G} \Omega$. $\boldsymbol{B}$, Rare response from an untreated GABAergic neuron following a $200 \mathrm{~ms}$ puff of $300 \mu \mathrm{m} \mathrm{ACh}$. C, Graph of average peak current amplitudes from all untreated WT and nicotine-treated WT putative DA neurons. $\boldsymbol{D}$, $\boldsymbol{E}$, Average waveforms of $300 \mu \mathrm{m} \mathrm{ACh}$-evoked currents from single trials in putative DA neurons belonging to untreated (D) or nicotine-treated (E) groups before (black traces) and after (blue traces) application of $80 \mathrm{nM} \alpha$-CTX MII. $\boldsymbol{F}$, Percentage of control values from untreated and nicotine treated putative DA neurons following application of $\alpha$-CTX MII. In $\boldsymbol{C}$ and $\boldsymbol{F}$, the number of neurons measured is shown in parentheses for each bar. Error bars are \pm SEM, and $p$ values are based on Student's two-tailed $t$ test with unequal variance. ${ }^{*} p<0.05$.

no-drug and nicotine-treated cultured DA neurons mediated $41.2 \pm 5.1 \%$ and $48.4 \pm 3.9 \%$ of the response, respectively (Fig. $9 D-F)$.

In RNA-Seq data (Table 1), $\alpha 4$ signals are $\sim 10$-fold lower than $\alpha 6$ signals ( 21 vs 230 FPKM, respectively). Although RNASeq data provide good comparisons of mRNA abundance when compared within a single gene and across conditions, we have less confidence that RNA-Seq data reflect relative abundance of
nAChR subunit mRNAs across genes. We employ oligo-dT primers for cDNA synthesis, and this may introduce distortions for brain mRNAs, which have long $3^{\prime}$ untranslated regions. Furthermore, mRNA levels are not proportional to the level of protein that is expressed on the cell surface. Translation efficiency and protein half-life influence the correlation between mRNA and protein abundances. We emphasize that the functional data presented in Figure 9, $D-F$, show $\alpha 4^{*}$ and $\alpha 6^{*}$ nAChRs each mediate 
$\sim 50 \%$ of the ACh response, measured at the peak of the waveform, and this does not change markedly for the upregulated responses.

In only one cell (a saline-treated putative DA neuron), the waveform showed a rapidly desensitizing component (50-100 ms) that usually denotes $\alpha 7$ nAChRs (Xiao et al., 2009). In other experiments with $\alpha 7$-transfected cells, the instrumentation could reliably detect such responses (Xiao et al., 2015). This observation, along with lack of robust $\alpha 7$ RNA-Seq signals, leads us to believe that the ACh responses reflected primarily the activity of $\alpha 4 \beta 2^{\star}$ and $\alpha 6 \beta 2^{\star}$ rather than $\alpha 7$ nAChRs.

\section{Discussion}

Our data show that maintained exposure to a smoking-relevant nicotine concentration attenuates mild ER stress and the UPR in DA neurons (Figs. 3-5). Because most cases of PD progress over decades, neurodegeneration occurs via comparatively subtle pathophysiological processes. Rather than studying DA cell death, we therefore studied events caused by a minimal cellular stressor in long-term (three weeks) cultures of the mouse ventral midbrain, containing DA neurons (Fig. 2). Because prolonged, uncontrolled ER stress and the UPR are implicated in the pathogenesis of PD (Hoozemans et al., 2007), our results suggest that one neuroprotective mechanism for nicotine in DA neurons involves suppression of the UPR. We demonstrate for the first time that these cultured DA neurons express functional native $\alpha 4^{\star}$ and $\alpha 6^{\star}$ nAChRs, as well as $\beta 3$ subunits, a component of many $\alpha 6^{*}$ nAChRs (Fig. 7). We also show, by using transfected neuroblastoma cells, that nAChRs are required for nicotine-induced reduction in ER stress markers (Fig. 6).

The simplified nature of a culture system allows one to suspect that the effects occur in a cell-delimited fashion, independent of circuit influences on the DA neurons, but we cannot yet rule out indirect effects via nicotine actions on glia. Previous experiments using expression of nAChRs in Neuro-2a cells and neurons show that one such cell-delimited effect of low-dose nicotine is pharmacological chaperoning of nAChRs in the ER, leading to suppression of ER stress and the UPR (Srinivasan et al., 2012). This suggestion receives support because we observed an additional indicator of pharmacological chaperoning by nicotine: the classical observation that $\alpha 4 \beta 2^{\star}$ and some $\alpha 6 \beta 2^{\star}$ function is upregulated during chronic exposure to nicotine (Henderson and Lester 2015).

\section{Low-dose Tu induces, and nicotine suppresses, the UPR in cultured DA neurons}

We induced mild, prolonged ER stress by exposing WT cells to $\mathrm{Tu}$ at a lower dose (50 $\mathrm{nm})$ and for a longer time $(72 \mathrm{~h})$ than in previous studies (Shiraishi et al., 2006; Han et al., 2008; Sasaya et al., 2008; Bull and Thiede, 2012). Tu (50 nM) induced the upregulation and nuclear translocation of phosphorylated XBP1 (Fig. $4 C$ ) and eIF2 $\alpha$ (Fig. 5), but failed to affect ATF6 (Fig. 4E). Tu (50 $\mathrm{nM}, 48 \mathrm{~h}$ ) induced the upregulation and nuclear translocation of $\mathrm{CHOP}$, which is considered a major apoptotic effector of the UPR (Fig. 3). This suggests that ATF6 does not lie upstream of CHOP activation in cultured DA neurons. Significant nuclear translocation of ATF6 did occur with a 20-fold higher concentration of Tu (1 $\mu \mathrm{M}$ for $48 \mathrm{~h}$; Fig. $4 F$ ).

Baseline levels of XBP1, phosphorylated eIF2 $\alpha$, and CHOP were unaffected by a 2 week exposure to $200 \mathrm{~nm}$ nicotine (Figs. 3-5). Nicotine modestly reduced baseline levels of ATF6 in the nucleus (Fig. 4D), suggesting that DA neurons may experience mild, physiological ER stress due to cyclical $\mathrm{Ca}^{+2}$ influx (Sur- meier et al., 2011) and/or toxic metabolites of DA (Ahmadi et al., 2008; Miyazaki and Asanuma, 2009).

Nicotine inhibited the Tu-induced upregulation and nuclear translocation of XBP1, ATF6, and phosphorylated eIF2 $\alpha$ (Figs. 4, $5)$. Thus, chronic nicotine at smoking-relevant concentrations, acting via $\mathrm{nAChRs,} \mathrm{displays} \mathrm{a} \mathrm{global} \mathrm{inhibitory} \mathrm{effect} \mathrm{on} \mathrm{all} \mathrm{arms}$ of the UPR pathway.

\section{Which $\mathrm{nAChR}(\mathrm{s})$ participate in neuroprotection in DA neurons?}

Using three strains of mice with fluorescent $\mathrm{nAChR}$ subunits, we found $\alpha 4, \alpha 6$, and $\beta 3 \mathrm{nAChR}$ subunits in cultured DA neurons and their neurites (Fig. 7). Responses to ACh indicated that the endogenous $\mathrm{nAChR}$ receptor subunits do form functional heteropentamers (Fig. 9). Because $\alpha 4^{\star}$ and $\alpha 6^{\star}$ nAChRs require $\beta 2$ subunits to form functional pentamers on the PM (Whiteaker et al., 2006), we infer that the cultured DA neurons also express $\beta 2$ subunits. Compared to DA neurons, TH-negative GABAergic neurons (Fig. 9B) had few ACh responses; as expected, they had no detectable $\alpha 6$ or $\beta 3$ subunits.

In DA neurons, ACh-induced current waveforms (Fig. 9A) and pharmacology show that the responses are generated predominantly by both $\alpha 4 \beta 2^{\star}$ and $\alpha 6 \beta 2^{\star}$ nAChRs, and not by $\alpha 7$ nAChRs. Chronic nicotine caused a more than twofold increase in peak nAChR current amplitudes (Fig. 9A, C), a typical value in the upregulation literature. Previous data on adult DA neurons show that chronic exposure to nicotine upregulates somatodendritic $\alpha 6^{*}$ nAChRs, but not somatodendritic $\alpha 4^{*}$ nAChRs (Nashmi et al., 2007; Xiao et al., 2009; Henderson et al., 2014). However, the similar effects of $\alpha$-CTX MII exposure on the untreated versus upregulated responses in cultured neurons (Fig. 9D-F) suggest that both $\alpha 4^{*}$ and $\alpha 6^{*}$ somatodendritic nAChRs are upregulated.

RNA-Seq data from single neurons confirmed that cultured DA neurons express $\alpha 4, \alpha 6, \beta 2$, and $\beta 3$ nAChR subunit mRNAs (Henley et al., 2013). Our single-cell RNA-Seq data (Henley et al., 2013; Table 1) show coexpression of TH and other DA-related transcripts in addition to $\mathrm{nAChR}$ mRNAs in DA neurons.

Future work may further specify the subtype(s) of nAChR that subserve neuroprotection in culture. Adult DA neurons express various nAChR subtypes in vivo, but this is the first study to specify in vitro conditions that allow the expression and measurement of so-called high-sensitivity nAChRs, presumably of the $\alpha 4 \beta 2^{\star}$ and $\alpha 6 \beta 2^{\star}$ families, which are activated, desensitized, and upregulated by smoking-relevant nicotine concentrations in DA neurons. Other studies suggest that $\alpha 4 \beta 2^{\star}$ and $\alpha 6 \beta 2^{\star}$ nAChRs are necessary for PD neuroprotection (Ryan et al., 2001; Quik and Wonnacott, 2011). A study on apparent protection against $\mathrm{Tu}$ effects by nicotine in PC12 cells found protection at nonsmoking-relevant concentrations of 50-500 $\mu \mathrm{M}$ nicotine, $>100$ fold greater than the concentrations studied here (Sasaya et al., 2008). This is consistent with the known presence of $\alpha 7$ and $\alpha 3 \beta 4$ nAChRs, but of neither $\alpha 4^{\star}$ nor $\alpha 6^{\star}$ nAChRs, in PC12 cells.

Our ACh response waveforms and RNA-Seq data reveal little or no contribution from $\alpha 7 \mathrm{nAChRs}$. Previous studies suggesting involvement of $\alpha 7 \mathrm{nAChRs}$ in neuroprotection by nicotine have used necrosis or apoptosis as an end point (Jonnala and Buccafusco, 2001; Toulorge et al., 2011), rather than the present, more subtle strategy of monitoring ER stress markers during ongoing pathology in DA neurons. Thus, $\alpha 7$ may participate in the final death of DA neurons rather than early pathological processes in PD. 


\section{Where is the "target" for nicotine neuroprotection in DA neurons?}

Nicotine's possible neuroprotective mechanisms fall into two major classes with regard to compartmentalization. "Outside-in" mechanisms occur because nicotine activates nAChRs on the plasma membrane, resulting in $\mathrm{Ca}^{2+}$ influx and the initiation of second messenger signaling cascades. $\mathrm{Ca}^{2+}$-induced changes in cellular transcription can partially explain the neuroprotective effects of nicotine in DA neurons (Belluardo et al., 1999; DajasBailador et al., 2000; Mudo et al., 2007; Toulorge et al., 2011).

"Inside-out" mechanisms occur because, in addition to activating surface receptors, nicotine permeates the neuronal plasma membrane and then enters the ER and other organelles in all cells (Kuryatov et al., 2005; Sallette et al., 2005; Lester et al., 2009; Miwa et al., 2011; Henderson and Lester 2015). In Neuro-2a cells and in cortical neurons overexpressing nAChRs, this process attenuates the UPR (Srinivasan et al., 2012); the present paper provides key support for the suggestion that similar processes occur at endogenous nAChR levels. Consequent changes in nuclear transcriptional processes might avert apoptotic ER stress response pathways implicated in PD.

In the present experiments, nicotine inhibited the nuclear translocation of CHOP, whereas the broad-spectrum nAChR channel blocker, mecamylamine, failed to suppress this effect (Fig. 3D). This is consistent with, but does not prove, an insideout mechanism, independent of plasma membrane nAChR activation. Another argument for inside-out mechanisms is that the nicotine concentration (200 nM) studied here, which gave UPR suppression and nAChR upregulation, is well below the $\mathrm{EC}_{50}$ value for most nAChRs, but above the $\mathrm{EC}_{50}$ value for pharmacological chaperoning by nicotine (Kuryatov et al., 2008).

Conceivably, processes in addition to pharmacological chaperoning participate in neuroprotection and/or upregulation. In some heterologous expression systems, upregulation occurs via decreased endocytosis from the plasma membrane as well as via chaperoning (Kuryatov et al., 2005; Sallette et al., 2005; Rezvani et al., 2010; Lomazzo et al., 2011; Srinivasan et al., 2011, 2012; Govind et al., 2012; Henderson and Lester 2015). Prolonged nicotine exposure at the plasma membrane induces high-affinity "desensitized" nicotine-nAChR complexes, but there is no evidence that plasma membrane desensitization affects endoplasmic reticulum stress, the unfolded protein response, upregulation, or neuroprotection (Henderson and Lester 2015).

\section{Possible therapeutic advantages of exploiting high-sensitivity native $\mathrm{nAChRs}$}

Previous authors suggested that therapeutic strategies to minimize proapoptotic aspects of the UPR might be neuroprotective during early-stage PD (Colla et al., 2012b). In addition to nicotine (a U.S. Food and Drug Administration approved drug) acting on $\mathrm{nAChRs}$, experimental compounds acting on other targets have been investigated to suppress the UPR in neurons (Colla et al., 2012b; Moreno et al., 2012; Sidrauski et al., 2013; Narayan et al., 2014). Unfortunately, the targets studied, such as eIF2 $\alpha$ and PERK, are generally expressed in all cell types, and the homeostatic UPR response is required for many aspects of normal function. Furthermore, salubrinal suppresses ER stress and delays the onset of disease in an $\alpha$-synuclein overexpression mouse model for $\mathrm{PD}$, but exacerbates another neurodegenerative disease model, prion-infected mice (Moreno et al., 2012). In contrast, inside-out effects of smoking, nicotine patches, or vaping occur only in neuronal cell types expressing high-sensitivity nAChRs, and for incompletely understood reasons, in only a subset of those (Henderson and Lester 2015). Thus, exploiting nAChRs to minimize ER stress in PD may have the advantage of cellular selectivity.

\section{References}

Abramoff M, Magelhaes P, SJ R (2004) Image processing with ImageJ. Biophotonics Int 11:36-42.

Ahmadi FA, Grammatopoulos TN, Poczobutt AM, Jones SM, Snell LD, Das M, Zawada WM (2008) Dopamine selectively sensitizes dopaminergic neurons to rotenone-induced apoptosis. Neurochem Res 33:886-901. CrossRef Medline

Belluardo N, Mudò G, Caniglia G, Cheng Q, Blum M, Fuxe K (1999) The nicotinic acetylcholine receptor agonist ABT-594 increases FGF-2 expression in various rat brain regions. Neuroreport 10:3909-3913. CrossRef Medline

Bull VH, Thiede B (2012) Proteome analysis of tunicamycin-induced ER stress. Electrophoresis 33:1814-1823. CrossRef Medline

Champtiaux N, Gotti C, Cordero-Erausquin M, David DJ, Przybylski C, Léna C, Clementi F, Moretti M, Rossi FM, Le Novère N, McIntosh JM, Gardier AM, Changeux JP (2003) Subunit composition of functional nicotinic receptors in dopaminergic neurons investigated with knock-out mice. J Neurosci 23:7820-7829. Medline

Chieng B, Azriel Y, Mohammadi S, Christie MJ (2011) Distinct cellular properties of identified dopaminergic and GABAergic neurons in the mouse ventral tegmental area. J Physiol 589:3775-3787. CrossRef Medline

Clarke PB, Pert A (1985) Autoradiographic evidence for nicotine receptors on nigrostriatal and mesolimbic dopaminergic neurons. Brain Res 348: 355-358. CrossRef Medline

Colla E, Jensen PH, Pletnikova O, Troncoso JC, Glabe C, Lee MK (2012a) Accumulation of toxic alpha-synuclein oligomer within endoplasmic reticulum occurs in alpha-synucleinopathy in vivo. J Neurosci 32:33013305. CrossRef Medline

Colla E, Coune P, Liu Y, Pletnikova O, Troncoso JC, Iwatsubo T, Schneider BL, Lee MK (2012b) Endoplasmic reticulum stress is important for the manifestations of $\alpha$-synucleinopathy in vivo. J Neurosci 32:3306-3320. CrossRef Medline

Costa G, Abin-Carriquiry JA, Dajas F (2001) Nicotine prevents striatal dopamine loss produced by 6-hydroxydopamine lesion in the substantia nigra. Brain Res 888:336-342. CrossRef Medline

Dajas-Bailador FA, Lima PA, Wonnacott S (2000) The $\alpha 7$ nicotinic acetylcholine receptor subtype mediates nicotine protection against NMDA excitotoxicity in primary hippocampal cultures through a $\mathrm{Ca}(2+)$ dependent mechanism. Neuropharmacology 39:2799-2807. CrossRef Medline

Drenan RM, Grady SR, Whiteaker P, McClure-Begley T, McKinney S, Miwa J, Bupp S, Heintz N, McIntosh JM, Bencherif M, Marks MJ, Lester HA (2008) In vivo activation of midbrain dopamine neurons via sensitized, high-affinity $\alpha 6^{*}$ nicotinic acetylcholine receptors. Neuron 60:123-136. CrossRef Medline

Fagerstrom KO, Pomerleau O, Giordani B, Stelson F (1994) Nicotine may relieve symptoms of Parkinson's disease. Psychopharmacology (Berl) 116:117-119. CrossRef

Ford CP, Mark GP, Williams JT (2006) Properties and opioid inhibition of mesolimbic dopamine neurons vary according to target location. J Neurosci 26:2788-2797. CrossRef Medline

Galehdar Z, Swan P, Fuerth B, Callaghan SM, Park DS, Cregan SP (2010) Neuronal apoptosis induced by endoplasmic reticulum stress is regulated by ATF4-CHOP-mediated induction of the Bcl-2 homology 3-only member PUMA. J Neurosci 30:16938-16948. CrossRef Medline

Gong S, Zheng C, Doughty ML, Losos K, Didkovsky N, Schambra UB, Nowak NJ, Joyner A, Leblanc G, Hatten ME, Heintz N (2003) A gene expression atlas of the central nervous system based on bacterial artificial chromosomes. Nature 425:917-925. CrossRef Medline

Govind AP, Walsh H, Green WN (2012) Nicotine-induced upregulation of native neuronal nicotinic receptors is caused by multiple mechanisms. J Neurosci 32:2227-2238. CrossRef Medline

Haataja L, Gurlo T, Huang CJ, Butler PC (2008) Many commercially available antibodies for detection of CHOP expression as a marker of endoplasmic reticulum stress fail specificity evaluation. Cell Biochem Biophys 51:105-107. CrossRef Medline

Han C, Nam MK, Park HJ, Seong YM, Kang S, Rhim H (2008) Tunicamycin-induced ER stress upregulates the expression of mitochon- 
drial HtrA2 and promotes apoptosis through the cytosolic release of HtrA2. J Microbiol Biotechnol 18:1197-1202. Medline

He C, Chen F, Li B, Hu Z (2014) Neurophysiology of HCN channels: from cellular functions to multiple regulations. Prog Neurobiol 112:1-23. CrossRef Medline

Henderson BJ, Lester HA (2015) Inside-out neuropharmacology of nicotinic drugs. Neuropharmacology 96:178-193. CrossRef Medline

Henderson BJ, Srinivasan R, Nichols WA, Dilworth CN, Gutierrez DF, Mackey ED, McKinney S, Drenan RM, Richards CI, Lester HA (2014) Nicotine exploits a COPI-mediated process for chaperone-mediated upregulation of its receptors. J Gen Physiol 143:51-66. Medline

Henley BM, Williams BA, Srinivasan R, Cohen BN, Xiao C, Mackey ED, Wold BJ, Lester HA (2013) Transcriptional regulation by nicotine in dopaminergic neurons. Biochem Pharmacol 86:1074-1083. CrossRef Medline

Hernán MA, Takkouche B, Caamaño-Isorna F, Gestal-Otero JJ (2002) A meta-analysis of coffee drinking, cigarette smoking, and the risk of Parkinson's disease. Ann Neurol 52:276-284. CrossRef Medline

Hoozemans JJ, van Haastert ES, Eikelenboom P, de Vos RA, Rozemuller JM, Scheper W (2007) Activation of the unfolded protein response in Parkinson's disease. Biochem Biophys Res Commun 354:707-711. CrossRef Medline

Jonnala RR, Buccafusco JJ (2001) Relationship between the increased cell surface $\alpha 7$ nicotinic receptor expression and neuroprotection induced by several nicotinic receptor agonists. J Neurosci Res 66:565-572. CrossRef Medline

Kelton MC, Kahn HJ, Conrath CL, Newhouse PA (2000) The effects of nicotine on Parkinson's disease. Brain Cogn 43:274-282. Medline

Kuryatov A, Luo J, Cooper J, Lindstrom J (2005) Nicotine acts as a pharmacological chaperone to up-regulate human $\alpha 4 \beta 2$ acetylcholine receptors. Mol Pharmacol 68:1839-1851. Medline

Kuryatov A, Onksen J, Lindstrom J (2008) Roles of accessory subunits in $\alpha 4 \beta 2 \alpha 5$ nicotinic receptors. Mol Pharmacol 74:132-143. CrossRef Medline

Lester HA, Xiao C, Srinivasan R, Son CD, Miwa J, Pantoja R, Banghart MR, Dougherty DA, Goate AM, Wang JC (2009) Nicotine is a selective pharmacological chaperone of acetylcholine receptor number and stoichiometry. Implications for drug discovery. AAPS J 11:167-177. CrossRef Medline

Lomazzo E, Hussmann GP, Wolfe BB, Yasuda RP, Perry DC, Kellar KJ (2011) Effects of chronic nicotine on heteromeric neuronal nicotinic receptors in rat primary cultured neurons. J Neurochem 119:153-164. CrossRef Medline

Mackey ED, Engle SE, Kim MR, O’Neill HC, Wageman CR, Patzlaff NE, Wang Y, Grady SR, McIntosh JM, Marks MJ, Lester HA, Drenan RM (2012) $\alpha 6^{*}$ nicotinic acetylcholine receptor expression and function in a visual salience circuit. J Neurosci 32:10226-10237. CrossRef Medline

Maggio R, Riva M, Vaglini F, Fornai F, Molteni R, Armogida M, Racagni G, Corsini GU (1998) Nicotine prevents experimental parkinsonism in rodents and induces striatal increase of neurotrophic factors. J Neurochem 71:2439-2446. Medline

Marciniak SJ, Yun CY, Oyadomari S, Novoa I, Zhang Y, Jungreis R, Nagata K, Harding HP, Ron D (2004) CHOP induces death by promoting protein synthesis and oxidation in the stressed endoplasmic reticulum. Genes Dev 18:3066-3077. CrossRef Medline

Marks MJ, Stitzel JA, Collins AC (1985) Time course study of the effects of chronic nicotine infusion on drug response and brain receptors. J Pharmacol Exp Ther 235:619-628. Medline

Matta SG, Balfour DJ, Benowitz NL, Boyd RT, Buccafusco JJ, Caggiula AR, Craig CR, Collins AC, Damaj MI, Donny EC, Gardiner PS, Grady SR, Heberlein U, Leonard SS, Levin ED, Lukas RJ, Markou A, Marks MJ, McCallum SE, Parameswaran N, et al. (2007) Guidelines on nicotine dose selection for in vivo research. Psychopharm 190:269-319. CrossRef

Mercado G, Valdés P, Hetz C (2013) An ERcentric view of Parkinson's disease. Trends Mol Med 19:165-175. CrossRef Medline

Mitsuoka T, Kaseda Y, Yamashita H, Kohriyama T, Kawakami H, Nakamura S, Yamamura Y (2002) Effects of nicotine chewing gum on UPDRS score and P300 in early-onset parkinsonism. Hiroshima J Med Sci 51: 33-39. Medline

Miwa JM, Freedman R, Lester HA (2011) Neural systems governed by nicotinic acetylcholine receptors: emerging hypotheses. Neuron 70:20-33. CrossRef Medline
Miyazaki I, Asanuma M (2009) Approaches to prevent dopamine quinoneinduced neurotoxicity. Neurochem Res 34:698-706. CrossRef Medline

Moreno JA, Radford H, Peretti D, Steinert JR, Verity N, Martin MG, Halliday M, Morgan J, Dinsdale D, Ortori CA, Barrett DA, Tsaytler P, Bertolotti A, Willis AE, Bushell M, Mallucci GR (2012) Sustained translational repression by eIF2alpha-P mediates prion neurodegeneration. Nature 485: 507-511. Medline

Mudo G, Belluardo N, Fuxe K (2007) Nicotinic receptor agonists as neuroprotective/neurotrophic drugs. Progress in molecular mechanisms. J Neural Transm 114:135-147. CrossRef Medline

Narayan P, Ehsani S, Lindquist S (2014) Combating neurodegenerative disease with chemical probes and model systems. Nat Chem Biol 10:911920. CrossRef Medline

Nashmi R, Xiao C, Deshpande P, McKinney S, Grady SR, Whiteaker P, Huang Q, McClure-Begley T, Lindstrom JM, Labarca C, Collins AC, Marks MJ, Lester HA (2007) Chronic nicotine cell specifically upregulates functional $\alpha 4^{\star}$ nicotinic receptors: basis for both tolerance in midbrain and enhanced long-term potentiation in perforant path. J Neurosci 27:82028218. CrossRef Medline

Pruszak J, Just L, Isacson O, Nikkhah G (2009) Isolation and culture of ventral mesencephalic precursor cells and dopaminergic neurons from rodent brains. Curr Protoc Stem Cell Biol Chapter 2:Unit 2D.5. Medline

Quik M, WonnacottS (2011) $\alpha 6 \beta 2^{*}$ and $\alpha 4 \beta 2^{*}$ nicotinic acetylcholine receptors as drug targets for Parkinson's disease. Pharmacol Rev 63:938966. CrossRef Medline

Rezvani K, Teng Y, De Biasi M (2010) The ubiquitin-proteasome system regulates the stability of neuronal nicotinic acetylcholine receptors. J Mol Neurosci 40:177-184. CrossRef Medline

Ritz B, Ascherio A, Checkoway H, Marder KS, Nelson LM, Rocca WA, Ross GW, Strickland D, Van Den Eeden SK, Gorell J (2007) Pooled analysis of tobacco use and risk of Parkinson disease. Arch Neurol 64:990-997. CrossRef Medline

Ryan RE, Ross SA, Drago J, Loiacono RE (2001) Dose-related neuroprotective effects of chronic nicotine in 6-hydroxydopamine treated rats, and loss of neuroprotection in $\alpha 4$ nicotinic receptor subunit knockout mice. Br J Pharmacol 132:1650-1656. CrossRef Medline

Sallette J, Pons S, Devillers-Thiery A, Soudant M, Prado de Carvalho L, Changeux JP, Corringer PJ (2005) Nicotine upregulates its own receptors through enhanced intracellular maturation. Neuron 46:595-607. CrossRef Medline

Sasaya H, Utsumi T, Shimoke K, Nakayama H, Matsumura Y, Fukunaga K, Ikeuchi T (2008) Nicotine suppresses tunicamycin-induced, but not thapsigargin-induced, expression of GRP78 during ER stress-mediated apoptosis in PC12 cells. J Biochem 144.

Schwartz RD, Kellar KJ (1985) In vivo regulation of $\left[{ }^{3} \mathrm{H}\right]$ acetylcholine recognition sites in brain by nicotinic cholinergic drugs. J Neurochem 45 : 427-433. CrossRef Medline

Schwartz RD, Lehmann J, Kellar KJ (1984) Presynaptic nicotinic cholinergic receptors labeled by $[3 \mathrm{H}]$ acetylcholine on catecholamine and serotonin axons in brain. J Neurochem 42:1495-1498. CrossRef Medline

Shih PY, Engle SE, Oh G, Deshpande P, Puskar NL, Lester HA, Drenan RM (2014) Differential expression and function of nicotinic acetylcholine receptors in subdivisions of medial habenula. J Neurosci 34:9789-9802. CrossRef Medline

Shiraishi H, Okamoto H, Yoshimura A, Yoshida H (2006) ER stressinduced apoptosis and caspase-12 activation occurs downstream of mitochondrial apoptosis involving Apaf-1. J Cell Sci 119:3958-3966. CrossRef Medline

Sidrauski C, Acosta-Alvear D, Khoutorsky A, Vedantham P, Hearn BR, Li H, Gamache K, Gallagher CM, Ang KK, Wilson C, Okreglak V, Ashkenazi A, Hann B, Nader K, Arkin MR, Renslo AR, Sonenberg N, Walter P (2013) Pharmacological brake-release of mRNA translation enhances cognitive memory. Elife 2:e00498. Medline

Silva RM, Ries V, Oo TF, Yarygina O, Jackson-Lewis V, Ryu EJ, Lu PD, Marciniak SJ, Ron D, Przedborski S, Kholodilov N, Greene LA, Burke RE (2005) CHOP/GADD153 is a mediator of apoptotic death in substantia nigra dopamine neurons in an in vivo neurotoxin model of parkinsonism. J Neurochem 95:974-986. CrossRef Medline

Srinivasan R, Pantoja R, Moss FJ, Mackey ED, Son CD, Miwa J, Lester HA (2011) Nicotine upregulates $\alpha 4 \beta 2$ nicotinic receptors and ER exit sites via stoichiometry-dependent chaperoning. J Gen Physiol 137:59-79. Medline 
Srinivasan R, Richards CI, Xiao C, Rhee D, Pantoja R, Dougherty DA, Miwa JM, Lester HA (2012) Pharmacological chaperoning of nicotinic acetylcholine receptors reduces the endoplasmic reticulum stress response. Mol Pharmacol 81:759-769. CrossRef Medline

Surmeier DJ, Guzman JN, Sanchez-Padilla J, Schumacker PT (2011) The role of calcium and mitochondrial oxidant stress in the loss of substantia nigra pars compacta dopaminergic neurons in Parkinson's disease. Neuroscience 198:221-231. CrossRef Medline

Tanner CM, Goldman SM, Aston DA, Ottman R, Ellenberg J, Mayeux R, Langston JW (2002) Smoking and Parkinson's disease in twins. Neurology 58:581-588. CrossRef Medline

Tapper AR, McKinney SL, Nashmi R, Schwarz J, Deshpande P, Labarca C, Whiteaker P, Marks MJ, Collins AC, Lester HA (2004) Nicotine activation of $\alpha 4^{*}$ receptors: sufficient for reward, tolerance and sensitization. Science 306:1029-1032. CrossRef Medline

Toulorge D, Guerreiro S, Hild A, Maskos U, Hirsch EC, Michel PP (2011) Neuroprotection of midbrain dopamine neurons by nicotine is gated by cytoplasmic $\mathrm{Ca}^{2+}$. Faseb J 25:2563-2573. CrossRef Medline

Trapnell C, Roberts A, Goff L, Pertea G, Kim D, Kelley DR, Pimentel H, Salzberg SL, Rinn JL, Pachter L (2012) Differential gene and transcript expression analysis of RNA-seq experiments with TopHat and Cufflinks. Nature Protocols 7:562-578. CrossRef Medline

Villafane G, Cesaro P, Rialland A, Baloul S, Azimi S, Bourdet C, Le Houezec J, Macquin-Mavier I, Maison P (2007) Chronic high dose transdermal nicotine in Parkinson's disease: an open trial. Eur J Neurol 14:1313-1316. CrossRef Medline
Whiteaker P, Cooper JF, Salminen O, Marks MJ, McClure-Begley TD, Brown RW, Collins AC, Lindstrom JM (2006) Immunolabeling demonstrates the interdependence of mouse brain $\alpha 4$ and $\beta 2$ nicotinic acetylcholine receptor subunit expression. J Comp Neurol 499:1016-1038. CrossRef Medline

Xiao C, Nashmi R, McKinney S, Cai H, McIntosh JM, Lester HA (2009) Chronic nicotine selectively enhances $\alpha 4 \beta 2^{\star}$ nicotinic acetylcholine receptors in the nigrostriatal dopamine pathway. J Neurosci 29:12428 12439. CrossRef Medline

Xiao C, Srinivasan R, Drenan RM, Mackey ED, McIntosh JM, Lester HA (2011) Characterizing functional $\alpha 6 \beta 2$ nicotinic acetylcholine receptors in vitro: mutant $\beta 2$ subunits improve membrane expression, and fluorescent proteins reveal responsive cells. Biochem Pharmacol 82:852-861. CrossRef Medline

Xiao C, Miwa JM, Henderson BJ, Wang Y, Deshpande P, McKinney SL, Lester HA (2015) Nicotinic receptor subtype-selective circuit patterns in the subthalamic nucleus. J Neurosci 35:3734-3746. CrossRef Medline

Zinszner H, Kuroda M, Wang X, Batchvarova N, Lightfoot RT, Remotti H, Stevens JL, Ron D (1998) CHOP is implicated in programmed cell death in response to impaired function of the endoplasmic reticulum. Genes Dev 12:982-995. CrossRef Medline

Zoli M, Moretti M, Zanardi A, McIntosh JM, Clementi F, Gotti C (2002) Identification of the nicotinic receptor subtypes expressed on dopaminergic terminals in the rat striatum. J Neurosci 22:8785-8789. Medline 